\title{
IMPROVED CATALYSTS FOR HEAVY OIL UPGRADING BASED ON ZEOLITE Y NANOPARTICLES ENCAPSULATED IN STABLE NANOPOROUS HOST
}

\author{
FIFTH SEMI-ANNUAL TECHNICAL PROGRESS REPORT
}

REPORT PERIOD: $\quad$ October1, 2004 -March 31, 2005

PRINCIPAL INVESTIGATOR: CONRAD INGRAM, Ph. D.

Co. PI

MARK MITCHELL, Ph. D.

REPORT DATE: May 1, 2005

GRANT NUMBER: $\quad$ DE- FG26-02NT41676

INSTITUTION: $\quad$ CLARK ATLANTA UNIVERSITY

223 JAMES P. BRAWLEY DRIVE

ATLANTA, GA 30314 


\section{ABSTRACT}

The objectives of this project are to synthesis nanocrystals of highly acidic zeolite Y, encapsulate them within the channels of mesoporous (nanoporous) silicates or nanoporous organosilicates and evaluate the "zeolite Y/Nanoporous host" composites as catalysts for the upgrading of heavy petroleum feedstocks. Our results to date are summarized as follows. The synthesis of high surface ordered nanoporous silica of expanded pore diameter of $25 \mathrm{~nm}$ (larger than the standard size of $8.4 \mathrm{~nm}$ ) using trimethylbenzene as a pore size expander was accomplished. The synthesis of zeolite Y nanoparticles with median pore size of approximately $50 \mathrm{~nm}$ (smaller than the $80 \mathrm{~nm}$ typically obtained with TMAOH) using combined TMABr/TMAOH as organic additives was also accomplished. The successful synthesis of zeoliteY/Nanoporous host composite materials by sequential combination of zeolite precursors and nanoporous material precursor mixtures was implied based on results from various characterization techniques such as X-Ray diffraction, infrared spectra, thermal analysis, porosimetry data. The resulting materials showed pore sizes up to $11 \mathrm{~nm}$, and infrared band at $570 \mathrm{~cm}^{-1}$ suggesting the presence of both phases. New results indicated that good quality highly ordered nanoporous silica host can be synthesized in the

presence of zeolite $\mathrm{Y}$ seed precursor depending on the amount of precursor added. Preliminary research on the catalytic performance of the materials is underway. Probe acid catalyzed reactions, such as the cracking of cumene is currently being conducted. Work in the immediate future will be focused on the following three areas: 1) Further characterization of all-silica and aluminosilicate mesoporous materials with expanded pore sizes up to $30 \mathrm{~nm}$ will continue; 2) Research efforts to reduce the average particle size of zeolite nanoparticles down to 35-30 nm will continue; 3) Further synthesis of ZeoliteY/Nanoporous host composite catalysts of improved structural and physicochemical characteristics will be conducted by changing the amount and chemistry of the zeolitic precursors added; and 4) Investigation on the catalytic properties of the materials using probe catalytic reactions (such as cumene cracking), followed by catalytic testing for heavy oil conversion. 


\section{DISCLAIMER}

This report was prepared as an account of work sponsored by an agency of the United Sates Government. Neither the United States Government nor any agency thereof, nor any of their employees, makes any warranty, express or implied, or assumes any legal liability or responsibility for the accuracy, completeness, or usefulness of any information, apparatus, product, or process disclosed, or represents that its use would not infringe privately owned rights. Reference herein, to any specific commercial product, process, or service by trade name, trademark, manufacturer or otherwise does not necessarily constitute or imply its endorsement, recommendation, or favoring by the United States Government or any agency thereof. The views and opinions of the authors expresses herein do not necessarily state or reflect those of the United States Government or any agency thereof. 


\section{EXECUTIVE SUMMARY}

The objectives of this project are to synthesis nanocrystals of highly acidic zeolite Y, encapsulate them within the channels of mesoporous (nanoporous) silicates or nanoporous organosilicates and evaluate the "zeolite Y/Nanoporous host" composites as catalysts for the upgrading of heavy petroleum feedstocks. In comparison to conventionally-used zeolite $\mathrm{Y}$ catalysts of micron size particles, the nanocrystals ( $<100 \mathrm{~nm}$ particle size) which will contain shorter path lengths, will allow faster diffusion of large hydrocarbon substrates and the catalysis products within and out of the zeolite's channels and cages $(<1 \mathrm{~nm}$ size). This is expected to significantly reduce catalysts deactivation and prolong catalysts life. Encapsulating zeolite Y nanocrystals within nanoporous materials is anticipated to its external surfaces and pore entrances of the zeolite from being blocked by large hydrocarbon substrates, since these substrates will initially be converted to small molecules by the nanoporous host (a catalyst in its own right). The project consists of four major tasks as follows: a) synthesis of the nanoparticles of zeolite $\mathrm{Y}$ (of different chemical compositions) using various techniques such as the addition of organic additives to conventional zeolite $\mathrm{Y}$ synthesis mixtures to suppress zeolite $\mathrm{Y}$ crystal growth; b) synthesis of nanoporous silicate host materials of up to $30 \mathrm{~nm}$ pore diameter. This was conducted using poly (alkylene oxide) copolymers as template around which inorganic silicate precursors are organized. Subsequently removal of the copolymer will yield a mesoporous material, the pore sizes of which will depend on the number of poly (alkylene oxide) units; (c) Synthesis of "zeolite Y/Nanporous Host" composite materials as potential catalysts and (d) evaluation of the composites as catalysts for the upgrading of heavy petroleum feedstocks.

Our progress to date is summarized as follows. The synthesis of high surface ordered nanoporous silica of expanded pore diameter of $25 \mathrm{~nm}$ (larger than the standard size of $8.4 \mathrm{~nm}$ ) using trimethylbenzene as a pore size expander was accomplished. The synthesis of zeolite Y nanoparticles with median pore size of approximately $50 \mathrm{~nm}$ (smaller than the $80 \mathrm{~nm}$ typically obtained with $\mathrm{TMAOH}$ ) using combined TMABr/TMAOH as organic additives was also accomplished. The successful synthesis of zeoliteY/Nanoporous host composite materials by sequential combination of zeolite precursors and nanoporous material precursor mixtures was implied based on results from various characterization techniques such as X-Ray diffraction, infrared spectra, thermal analysis, porosimetry data. The resulting materials showed pore sizes up to $11 \mathrm{~nm}$, and infrared band at $570 \mathrm{~cm}^{-1}$ suggesting the presence of both phases. Probe acid catalyzed reactions, such as the cracking of cumene is currently being conducted. New results indicated that good quality highly ordered nanoporous silica host can be synthesized in the presence of zeolite $\mathrm{Y}$ seed precursor depending on the amount of precursor added.

Work in the immediate future will be focused on the following three areas: 1) Further characterization of all-silica and aluminosilicate mesoporous materials with expanded pore sizes up to $30 \mathrm{~nm}$ will continue; 2) Research efforts to reduce the average particle size of zeolite nanoparticles down to 35-30 nm will continue; 3) Further synthesis of ZeoliteY/Nanoporous host composite catalysts of improved structural and physicochemical characteristics will be conducted by changing the amount and chemistry of the zeolitic precursors added; and 4) Investigation on the catalytic properties of the materials using probe catalytic reactions (such as cumene cracking), followed by catalytic testing for heavy oil conversion. 
Table of Contents

Page No.

I ABSTRACT 2

II DISCLAIMER 3

III EXECUTIVE SUMMARY 4

IV INTRODUCTION 6

$\begin{array}{lll}V & \text { RESEARCH PROGRESS } & 7\end{array}$

V-1 EXPERIMENTAL
V-1A Setting up the Catalytic Reactor

V-1B Improvements in the quality of the nanoporous phase 9 formed from the synthesis of zeolite Y/Nanoporous host composite

V-1C Verifying the Synthesis of All Silica Nanoporous Materials 10

V-1D Verifying the Synthesis of SBA-15 in Sulfuric Acid. 11

V-1E Investigation on Zeolite Y Synthesis $\quad 11$

V-1E-1 Synthesis of Standard Zeolite Y 11

V-1E-2 Synthesis of Zeolite Y Nanoparticles 12

V-1F Zeolite Y Precursor Preparation and its Crystallization 12

V-1G Synthesis of Zeolite Y/SBA-15 Composites 12

$\begin{array}{ll}\text { V-1H Characterization } & 13\end{array}$

VI RESULTS AND DISCUSSION

VI-1 Synthesis of All Silica Nanoporous Materials 13

VI-2 Comparison of Synthesis of Standard Zeolite Y and Zeolite Y 19 Nanoparticles

VI-3 Synthesis of Zeolite Y/SBA-15 composites 25

VII CONCLUSIONS

VIII FUTURE WORK

IX TECHNOLOGY/INFORMATION TRANSFER 33

X REFERENCES 
The objective of this project is to synthesis nanocrystals of highly acidic zeolite Y, encapsulate them within the channels of mesoporous (nanoporous) silicates or nanoporous organosilicates and evaluate the "zeolite Y/Nanoporous host" composites as catalysts for the upgrading of heavy petroleum feedstocks. In comparison to conventionally-used zeolite Y catalysts of micron size particles, the nanocrystals (< $100 \mathrm{~nm}$ particle size) which will contain shorter path lengths, will allow faster diffusion of large hydrocarbon substrates and the catalysis products within and out of the zeolite's channels and cages $(<1 \mathrm{~nm}$ size). This is expected to significantly reduce catalysts deactivation and prolong catalysts life. Encapsulating zeolite Y nanocrystals within the nanoporous materials will protect its external surfaces and pore entrances from being blocked by large hydrocarbon substrates, since these substrates will initially be converted to small molecules by the nanoporous host (a catalyst in its own right). The project consists of four major tasks as follows: a) synthesis of the nanoparticles of zeolite Y (of various chemical compositions) using various techniques such as the addition of organic additives to conventional zeolite $\mathrm{Y}$ synthesis mixtures to suppress zeolite Y crystal growth; b) synthesis of nanoporous silicate host materials of up to $30 \mathrm{~nm}$ pore diameter. This was conducted using poly (alkylene oxide) copolymers as template around which inorganic silicate precursors are organized. Subsequently removal of the copolymer will yield a mesoporous material, the pore sizes of which will depend on the number of poly (alkylene oxide) units; (d) Synthesis of zeolite Y/Nanporous Host composite materials as potential catalysts and (d) catalysts evaluation for the upgrading of heavy petroleum feedstocks.

For this reporting period, the main accomplishments were: 1) the setting up of a microreactor for acid catalyzed reactions, and 2) improvements in the quality of the nanoporous phase formed from the synthesis of zeolite Y/Nanoporous host composite. Prior research progress leading up to this point is summarized as follows: The synthesis of high surface ordered nanoporous silica of expanded pore diameter of $25 \mathrm{~nm}$ (larger than the standard size of $8.4 \mathrm{~nm}$ ) using trimethylbenzene as a pore size expander was accomplished. The synthesis of zeolite Y nanoparticles with median pore size of approximately $50 \mathrm{~nm}$ (smaller than the $80 \mathrm{~nm}$ typically 
obtained with TMAOH) using combined TMABr/TMAOH as organic additives was also accomplished. The successful synthesis of zeoliteY/Nanoporous host composite materials by sequential combination of zeolite precursor mixtures and nanoporous material precursor mixtures was suggested from results from various characterization techniques such as X-Ray diffraction, infrared spectra, thermal analysis, porosimetry data.

Work in the immediate future will be focused on the following three areas: 1) Further characterization of all-silica and aluminosilicate mesoporous materials with expanded pore sizes up to $30 \mathrm{~nm}$ will continue; 2) Research efforts to reduce the average particle size of zeolite nanoparticles down to 35-30 nm will continue; 3) Further synthesis of ZeoliteY/Nanoporous host composite catalysts of improved structural and physicochemical characteristics; and 4) ) Investigation on the catalytic properties of the materials using probe catalytic reactions (such as cumene cracking), followed by catalytic testing for heavy oil conversion.

\section{RESEARCH PROGRESS}

\section{V-1 EXPERIMENTAL}

\section{V-1A Setting up the Catalytic Reactor}

A single pass fixed bed continuous flow reactor catalytic reactor interfaced with a Gas Chromatograph was set up for evaluating cumene cracking (Figure 1). The instrument is currently undergoing calibration prior to catalyst evaluation. For cumene cracking, a nitrogen stream will be saturated with cumene which is placed in a saturator, and subsequently carried at various space velocities over a catalyst bed $(\sim 0.5 \mathrm{gm})$ in a tube reactor which will be heated at a predetermined temperature and space velocity. The catalytic products will be sampled on-line using a 6 port sampling valve and injected onto the GC for analysis. Product distribution will be assessed for zeolite Y/Nnaocomposite host of various physicochemical characteristics. 

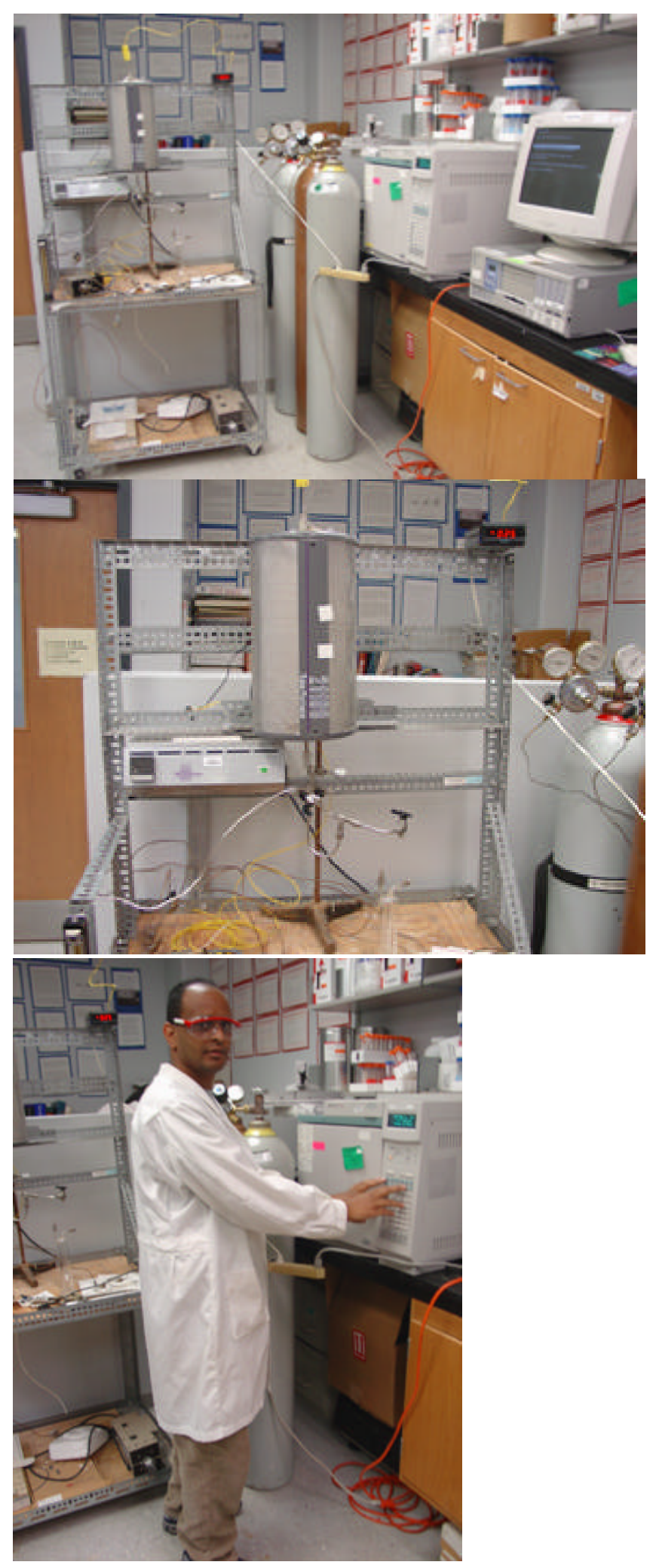

Figure 1. Pictorial of the single pass fixed bed continuous flow reactor catalytic reactor interfaced with for evaluating cumene cracking 


\section{V-1B Improvements in the quality of the nanoporous phase formed from the synthesis of zeolite Y/Nanoporous host composite}

In previous experiments, zeolite $\mathrm{Y}$ precursor mixtures were aged, diluted with tetraethylorthosilicate and converted to zeolite Y/Nanoporous host by adding copolymer P-123 and sulphuric acid. Based on X-Ray diffraction results, the products obtained were not as highly ordered as the pure Nanoporous host that was synthesized in the absence of the zeolite $\mathrm{Y}$ precursor. In this reporting period the effect of the amount of zeolite Y precursor on the nature of the nanoporous host products was investigated as follows: 4 gm P-123 was dissolved in 98 gm of water and $10 \mathrm{gm}$ of TEOS and 0.5, 1.5 and $3 \mathrm{gm}$ of zeolite Y precursor (which was previously aged at room temperature for 3 days followed by $100 \mathrm{C}$ for 1 day). The $\mathrm{pH}$ was adjusted to 5 by adding $1.7 \mathrm{M}$ sulfuric acid, the reaction continued at $40 \mathrm{C}$ for $24 \mathrm{hr}$, then $100 \mathrm{C}$ for 24 hours

Figures $2 \mathrm{~A}$ and $\mathrm{B}$ show XRD of products obtained when 1.5 and 3 of precursor was added respectively. In the case of $1.5 \mathrm{gm}$ added, the three sharp peaks characteristic of the targeted Nanoporous host (SBA-15) were identified between diffraction angles of 1 and 4 two theta.

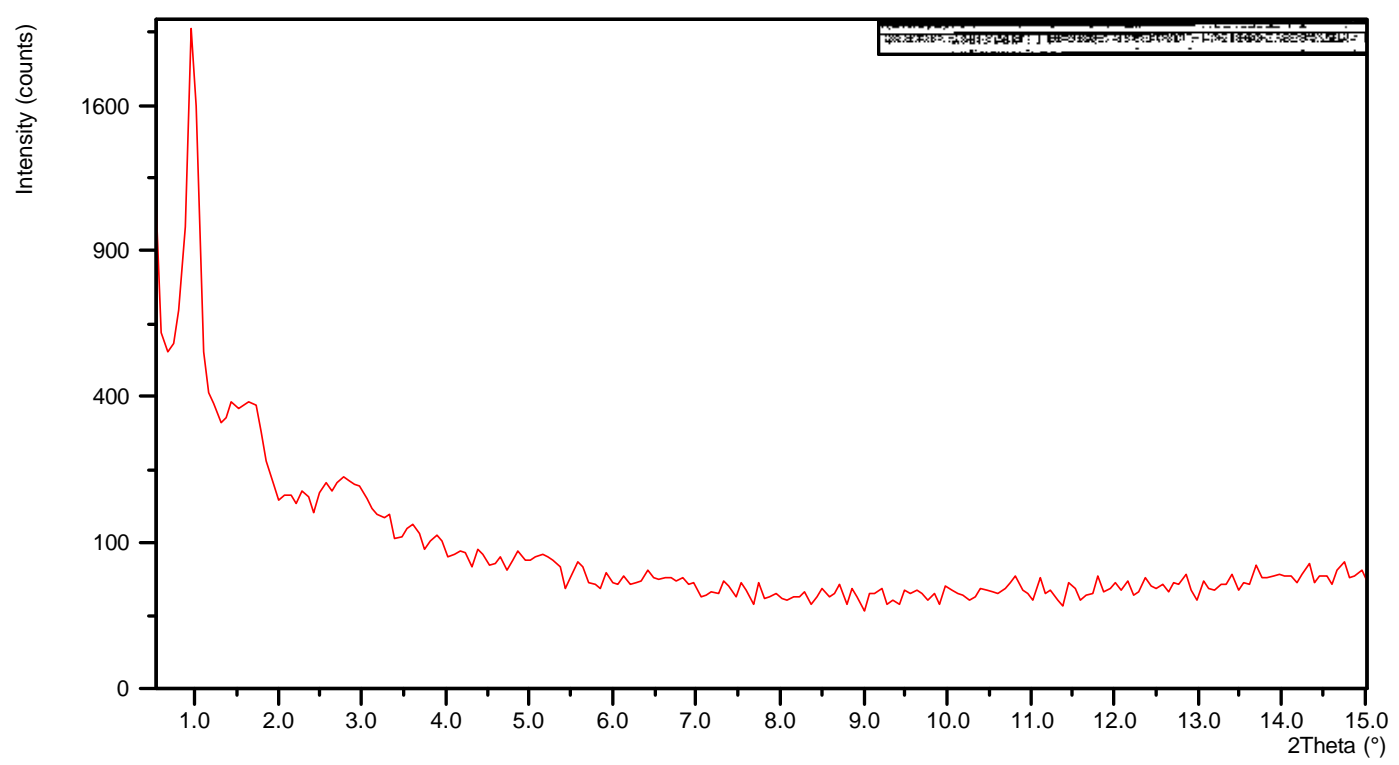

Figure 2A. XRD of zeoliteY/Nnaoporous host with $1.5 \mathrm{gm}$ of zeolite Y precursor added 


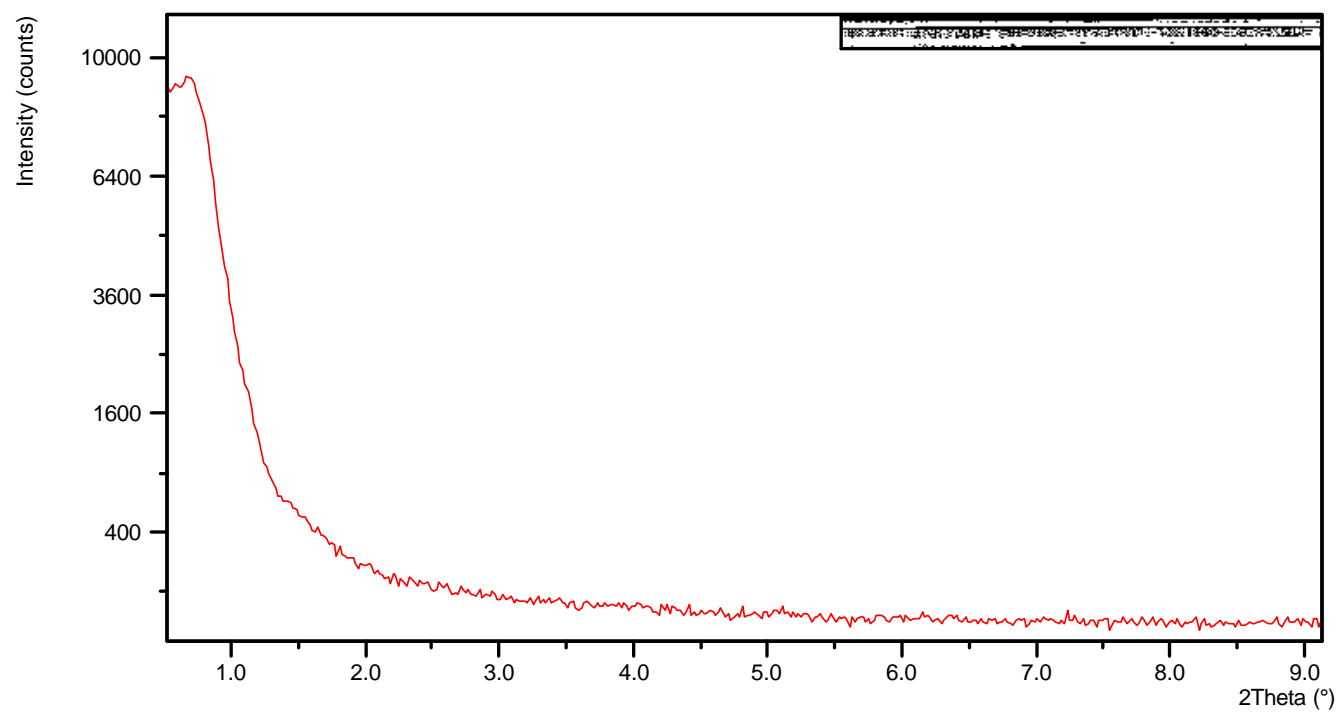

Figure 2B. XRD of zeoliteY/Nnaoporous host with $3 \mathrm{gm}$ of zeolite Y precursor added

When $3 \mathrm{gm}$ of precursor was added however, only one broad peak was observed in the product between diffraction angles of 1 and 4 two theta. The above observation demonstrated that the ration of the amount precursor to reactants affects the quality of the nanoporous products obtained. Further investigations into this is pending. Research prior to the above is highlighted below.

\section{V-1C Verifying the Synthesis of All Silica Nanoporous Materials}

All-silica nanoporous materials with expanded pore size were synthesized based on the method of Zhou et. al. ${ }^{1}$ Typically, 4.0 g of surfactant (Pluronic 123 block copolymer as templating agent), a known mass of 1,3,5 TMB, $30 \mathrm{~g}$ of $\mathrm{H}_{2} \mathrm{O}$ and $120 \mathrm{~g}$ of $2 \mathrm{M} \mathrm{HCl}$ solution were all mixed under vigorous stirring. $8.5 \mathrm{~g}$ of tetraethylorthosilicate (TEOS) was added to the homogenized mixture. The resulting mixture was continuously stirred for $24 \mathrm{~h}$ at $40^{\circ} \mathrm{C}$. The white solution was finally crystallized in a sealed, high density polyethylene bottle at $100^{\circ} \mathrm{C}$ for two days. The solid product was centrifuged, filtered, washed with deodorized water and dried in air at room temperature. The composition of the reaction mixture was as follows: $4.0 \mathrm{~g}$ P-123: $\mathrm{x} g \mathrm{~g}$ TMB: 0.041TEOS:0.24HCl:6.67 $\mathrm{H}_{2} \mathrm{O},($ where $\mathrm{x}=0.0,0.5,1.5,3.0,4.5,6.0 \mathrm{~g})$. 


\section{V-1D Verifying the Synthesis of SBA-15 in Sulfuric Acid.}

The first approach was to verify that the all silica mesoporous SBA-15 could effectively be synthesized in the presence of sulfuric acid $\left(\mathrm{H}_{2} \mathrm{SO}_{4}\right)$, rather than the widely used hydrochloric acid $(\mathrm{HCl})$ as described in IV-1A above. This was done since we observed that zeolite Y nanocrystals (particle size $<80 \mathrm{~nm}$ ) dissolved in the presence of $\mathrm{HCl}$ at $\mathrm{pH}<2$, but not in the presence of sulfuric acid. Therefore, any combination of zeolite $\mathrm{Y}$ and SBA-15 would have to done in $\mathrm{H}_{2} \mathrm{SO}_{4}$. The synthesis was conducted as follows; $4 \mathrm{gm}$ of copolymer, P-123, was dispersed in $30 \mathrm{gm}$ of $\mathrm{H}_{2} \mathrm{O}$ and $60 \mathrm{gm}$ of $2 \mathrm{M} \mathrm{H}_{2} \mathrm{SO}_{4}$ solution while stirring, followed by the addition $9 \mathrm{gm}$ of tetraethylorthosilicate (TEOS) to the homogenized solution. The compositional ratio of the mixture was: $4 \mathrm{~g}$ P-123:0.04TEOS:0.24 $\mathrm{H}_{2} \mathrm{SO}_{4}: 6.7 \mathrm{H}_{2} \mathrm{O}$. The gel mixture (with $\mathrm{pH} 1.6$ ) was continuously stirred for $24 \mathrm{hrs}$ at $35^{\circ} \mathrm{C}$, and then heated in a sealed polypropylene bottle at $100^{\circ} \mathrm{C}$ for one day (Sample ID.YG0304053). The solid product was centrifuged, filtered by suction, washed with deodorized water, dried in air at room temperature and calcined in air at $500^{\circ} \mathrm{C}$.

\section{V-1E Investigation on Zeolite Y Synthesis}

These experiments were conducted to investigate the presence and nature of these zeolite Y seeds and nanocrystals at various stages of synthesis, to determine what stages will be suitable for their incorporation in SBA-15.

\section{V-1E-1 Synthesis of Standard Zeolite Y}

Standard zeolite $\mathrm{Y}$ of submicron size was synthesized for comparison purposes according to procedure of Ginter. $^{2}$ The zeolite was synthesized from a sodium hydroxide: sodium aluminate:sodium silicate reaction mixture. Generally, a solution (Solution A) was first prepared by dissolving $20 \mathrm{~g}$ of water, $4.0 \mathrm{~g}$ of sodium hydroxide and $2.1 \mathrm{~g}$ sodium aluminate in a $50 \mathrm{ml}$ plastic bottle. A $23 \mathrm{~g}$ aliquot of sodium silicate solution was added, the mixture stirred for 10 minutes and left for 1 day at room temperature. A second solution, (Solution B) was simultaneously prepared by vigorously mixing $131 \mathrm{~g}$ of water, $0.14 \mathrm{~g}$ of sodium hydroxide and $13.1 \mathrm{~g}$ sodium aluminate in a beaker. Solutions A and B were combined under high shear mixing 
in high-speed blender, and left for one day at room temperature, followed by $22 \mathrm{~h}$ at $100^{\circ} \mathrm{C}$. The product was centrifuged, filtered, washed with deionized water, and dried at $110^{\circ} \mathrm{C}$.

\section{V-1E-2 Synthesis of Zeolite Y Nanoparticles}

The synthesis of zeolite Y nanoparticles was based on the presence of organic additives in the reaction mixture. The following reagents were used: $\mathrm{NaOH}$, aluminum isopropoxide$\left[\left(\mathrm{CH}_{3}\right)_{2} \mathrm{CHO}\right]_{3} \mathrm{Al}$, tetraethylorthosilicate (TEOS) $-\left(\mathrm{C}_{2} \mathrm{H}_{5} \mathrm{O}\right)_{4} \mathrm{Si}, 25 \mathrm{Wt} \%$ tetramethylammonium hydroxide (TMAOH)- $\left(\mathrm{C}_{2} \mathrm{H}_{5}\right)_{4} \mathrm{NOH}$, and tetramethylammonium bromide (TMABr) $-\left(\mathrm{C}_{2} \mathrm{H}_{5}\right)_{4} \mathrm{NBr}$. A general synthesis procedure was as follows: $12.8 \mathrm{~g}$ of $\left[\left(\mathrm{CH}_{3}\right)_{2} \mathrm{CHO}\right]_{3} \mathrm{Al}$ was dissolved in a solution of $52 \mathrm{~g}$ of $25 \mathrm{wt} \% \mathrm{TMAOH}, 0.59 \mathrm{~g}$ of $\mathrm{NaOH}$ and $78 \mathrm{~g}$ of water. Varying amounts of TMABr was then added, followed by $27.7 \mathrm{~g}$ of TEOS. The clear solution was stirred in a polypropylene bottle for 1 day at room temperature, followed by several days at $100^{\circ} \mathrm{C}$. The solid product was recovered by high speed centrifugation at $15000 \mathrm{~g}$ for 40 minutes.

\section{V-1F Zeolite Y Precursor Preparation and its Crystallization}

To prepare a typical zeolite Y precursor, $76.5 \mathrm{gm}$ of water, $52.3 \mathrm{gm}$ of tetramethylammonium hydroxide (TMAOH), $11.3 \mathrm{~g}$ of TMABr and $1.25 \mathrm{gm}$ of aluminum isopropoxide were mixed, followed by the addition of $32 \mathrm{gm}$ of TEOS. The mixture was stirred for 3 days at room temperature, then transferred to $100^{\circ} \mathrm{C}$ in oven for 7 days. The molar ratio of the reaction mixture with seed ID: YG022305 was: $1.0 \mathrm{Al}_{2} \mathrm{O}_{3}: 4.4 \mathrm{SiO}_{2}: 2.4 \mathrm{TMAOH}: 1.19 \mathrm{TMABr}: 0.048 \mathrm{Na}_{2} \mathrm{O}: 249 \mathrm{H}_{2} \mathrm{O}$. Aliquots of the precursor mixture were taken at different times, and the chemical composition and other synthesis conditions adjusted towards the synthesis of SBA-15 as described below.

\section{V-1G Synthesis of Zeolite Y/SBA-15 composites}

Aliquots of the zeolite $\mathrm{Y}$ precursor mixture above (IV-1D) were taken after various aging times and temperature, and were modified as follows. Typically, $36 \mathrm{gm}$ of aged precursor was mixed with $57 \mathrm{gm}$ of TEOS and the combined mixture heated at $100^{\circ} \mathrm{C}$ for $12 \mathrm{hrs}$. The Si/Al ratio in the

precursor was 5:1, and after addition of TEOS, the Si/Al ratio was 50:1. An amount of $15.5 \mathrm{gm}$ of the dilute heated mixture was then mixed with $4.5 \mathrm{gm}$ of polymer, $\mathrm{P}-123$, and $98.8 \mathrm{gm}$ of $1.7 \mathrm{M}$ 
of sulfuric acid. This final mixture was stirred for $30 \mathrm{hr}$ at $40^{\circ} \mathrm{C}$, then heated for $24 \mathrm{hr}$ at $100^{\circ} \mathrm{C}$. The solid product was filtered, washed, dried at room temperature and calcined at $500^{\circ} \mathrm{C}$. The final mixture had a molar composition ratio of $1.0 \mathrm{SiO}_{2}: 0.01 \mathrm{Al}_{2} \mathrm{O}_{3}: 0.013 \mathrm{P}-123: \mathrm{H}_{2} \mathrm{SO}_{4}: 70 \mathrm{H}_{2} \mathrm{O}$.

\section{V-1H Characterization}

Powdered X-ray diffraction measurements were performed on a Phillips X-Pert X-Ray Diffractometer using $\mathrm{Cu}-\mathrm{K}_{?}$ ? radiation (??= $\left.0.15418 \mathrm{~nm}\right)$. Nitrogen adsorption isotherms and BET surface area measurements were obtained using a Micromeritics ASAP 2020 Porosimeter. The samples were preheated at 200?C in nitrogen for $2 \mathrm{hr}$, and then evacuated before adsorption measurements. Atomic force microscopy (AFM) images were taken with a Thermomicroscopes AutoProbe CP Research Scanning Probe Microscope (SPM), a high-resolution SPM which employs ScanMaster, an optically based closed-loop position control system. It measures the sample position and corrects inherent piezo errors such as hysteresis, creep and cross coupling using a feedback loop. The 3-D surface topography was imaged with a gold-coated, V-shaped silicon nitride AFM cantilever having a spring constant of $0.5 \mathrm{~N} / \mathrm{m}$. Image sizes ranging from $2 \mathrm{x}$ 2 microns to $500 \times 500 \mathrm{~nm}$ were scanned at a rate of $500 \mathrm{~nm} / \mathrm{s}$. The samples were scanned in air in non-contact AFM mode using a cantilever resonant frequency of $117.08 \mathrm{kHz}$. Dynamic Light Scattering was done on a Horiba 500 Particle Size Analyzer. Infrared spectroscopy analysis was performed with a Nicolet 750 Magna Infrared Spectrophotometer. Samples were prepared by mixing, small quantities of finely ground sample with of the $\mathrm{KBr}$ powder, pressing a wafer and placing the latter in IR path. The infrared spectra were measured with a computer aid (OMNIC) software and 100 scans were acquired. Thermal analysis (TGA) was performed on a SDT 2960 from TA instruments Inc. Milligram quantities of sample were placed in an aluminum pan. The sample was heated from room temperature to $800^{\circ} \mathrm{C}$ at a heating rate of $10^{\circ} / \mathrm{min}$ in flowing air.

\section{RESULTS AND DISCUSSION}

\section{VI-1 Synthesis of All Silica Nanoporous Materials}

Figure 3 shows XRD of product obtained from the reaction mixture of molar composition $4.0 \mathrm{~g}$ P-123: 0g TMB: 0.041TEOS:0. $24 \mathrm{HCl}: 6.67 \mathrm{H}_{2} \mathrm{O}$. The three peaks observed (1 major peak at 2 
angle of $\sim 1^{\circ}$ and two smaller peaks at higher angles) are consistent with three dimensional hexagonally ordered nanoporous SBA-15. ${ }^{1}$ However, peaks in X-Ray diffraction patterns of samples synthesized in the presence of TMB, (not shown), could not be resolved from the very large background scattering generated by the instrument at very low angles. The presence of TMB in the synthesis mixture is expected to enlarge the pore diameters and unit cell size of SBA15 , thus shifting the diffraction peaks to lower 2 angles. At angles of less than $1^{\circ}$ significant background scattering was experienced on the XRD instrument, hence diffraction peaks, if present, could not be observed.

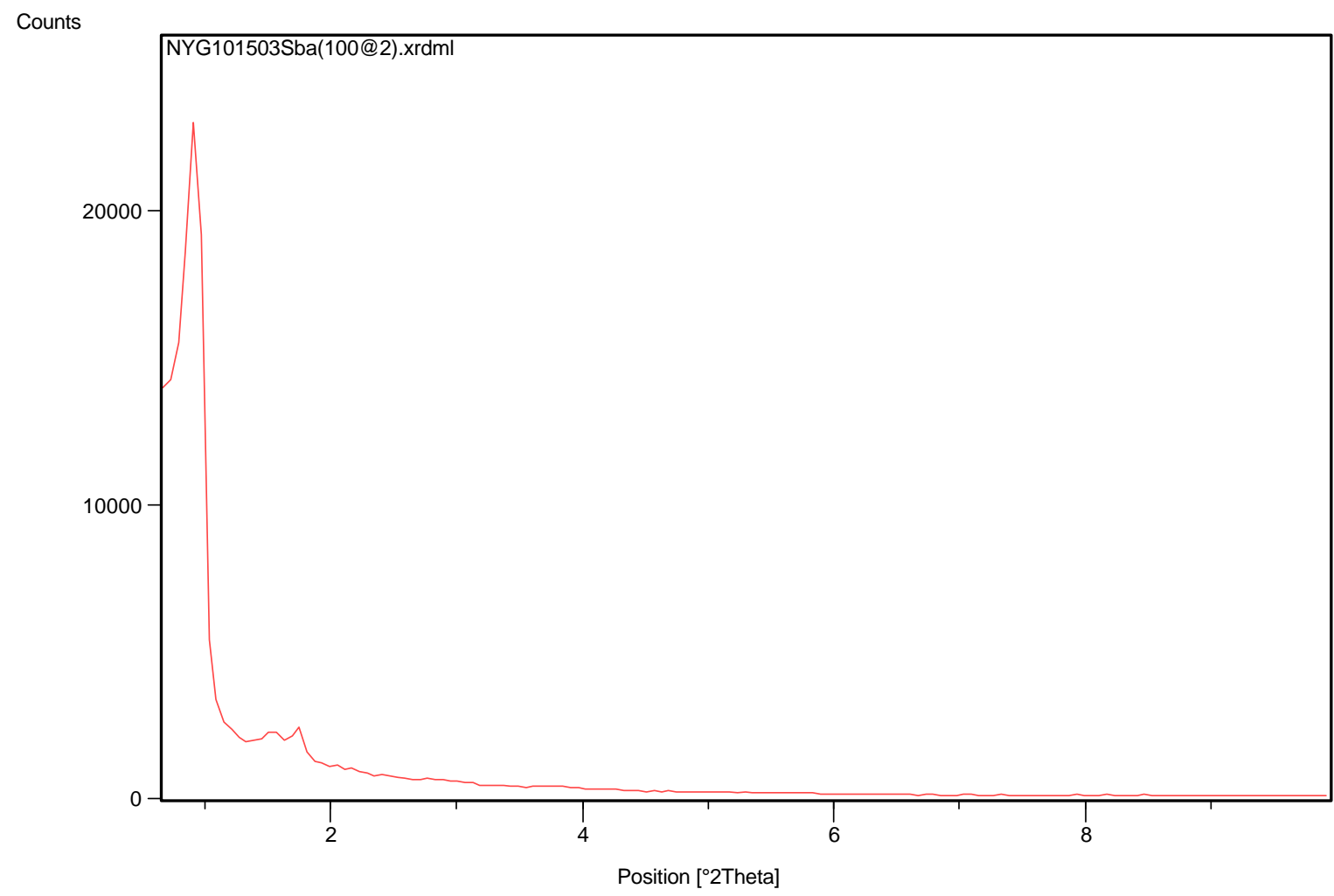

Figure 3. X-Ray Diffraction Pattern of the "as-synthesized" product obtained in the presence of $\mathrm{HCl}$ and surfactant $\mathrm{P}-123$.

In the interim, the pore size distributions in these samples were investigated using nitrogen porosimetry. Figure 4 (top) shows the adsorption-desorption isotherms from a standard SBA-15 synthesized in the absence of TMB. A type IV isotherm was observed confirming the nanoporous (mesoporous) nature of the material, with filling of nanopores commencing at P/Po around 0.74 
during the adsorption phase. A hysteresis loop, typical of this material was also observed at $\mathrm{P} / \mathrm{P}_{\mathrm{o}}$ values between 0.5 and 0.9 . The sample shows BET surface area of $653 \mathrm{~m}^{2} / \mathrm{g}$, pore volume 0.67 $\mathrm{cm}^{3} / \mathrm{g}$ and average $\mathrm{BJH}$ adsorption diameter of $8.4 \mathrm{~nm}$.

However, SBA -15 sample synthesized in the presence of TMB (Figure 4 bottom) shows adsorption-desorption isotherms with pore filling at $\mathrm{P} / \mathrm{Po}$ around 0.88 during the adsorption phase. The sample shows BET surface area of $466 \mathrm{~m}^{2} / \mathrm{g}$, pore volume of $1.13 \mathrm{~cm}^{3} / \mathrm{g}$ and average $\mathrm{BJH}$ adsorption pore diameter of $25 \mathrm{~nm}$. Pore size distribution curves for these samples are shown in Figure 5. Progress is therefore been made towards the synthesis of SBA-15 with expanded pore size in the range of $30 \mathrm{~nm}$.
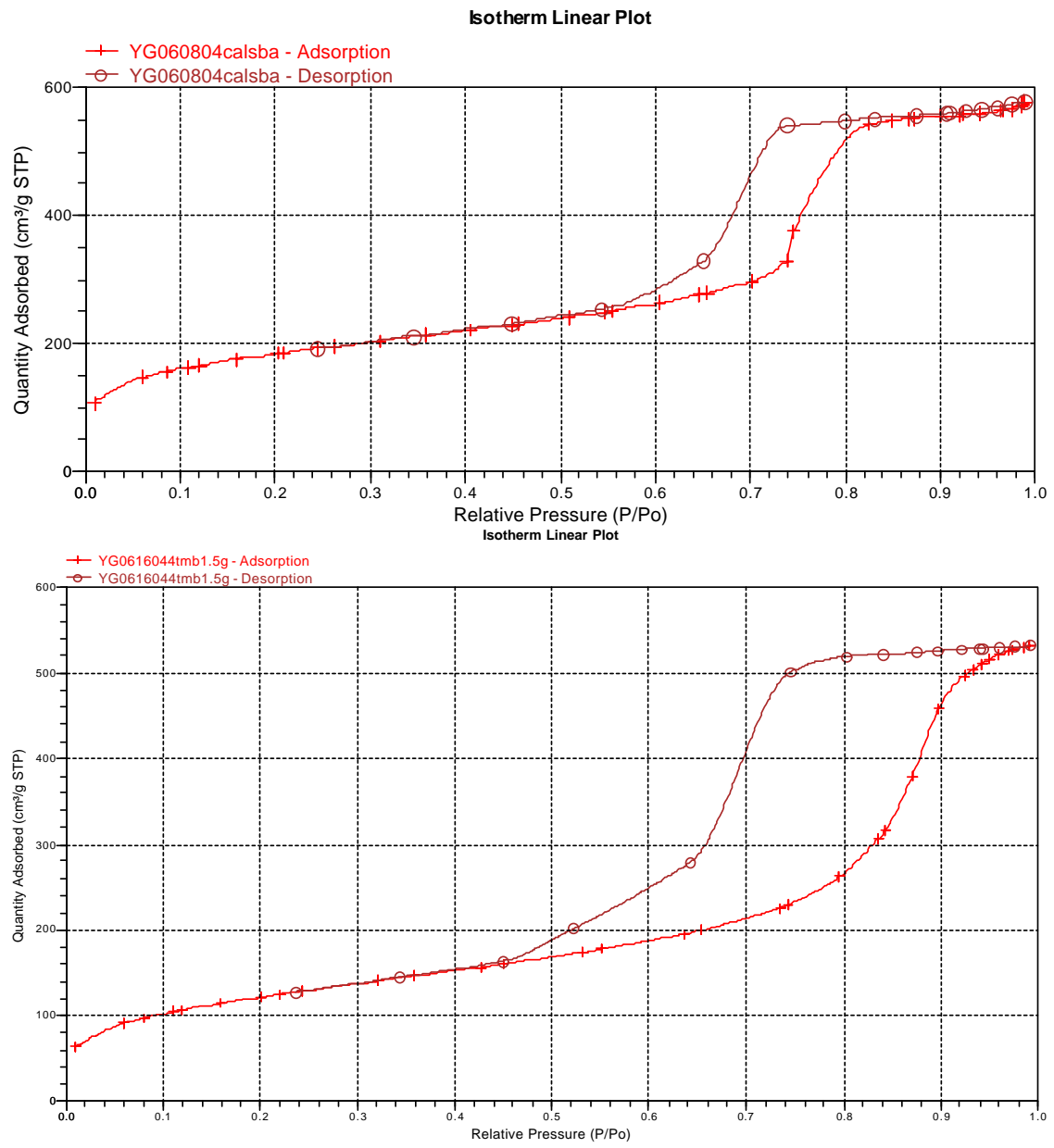


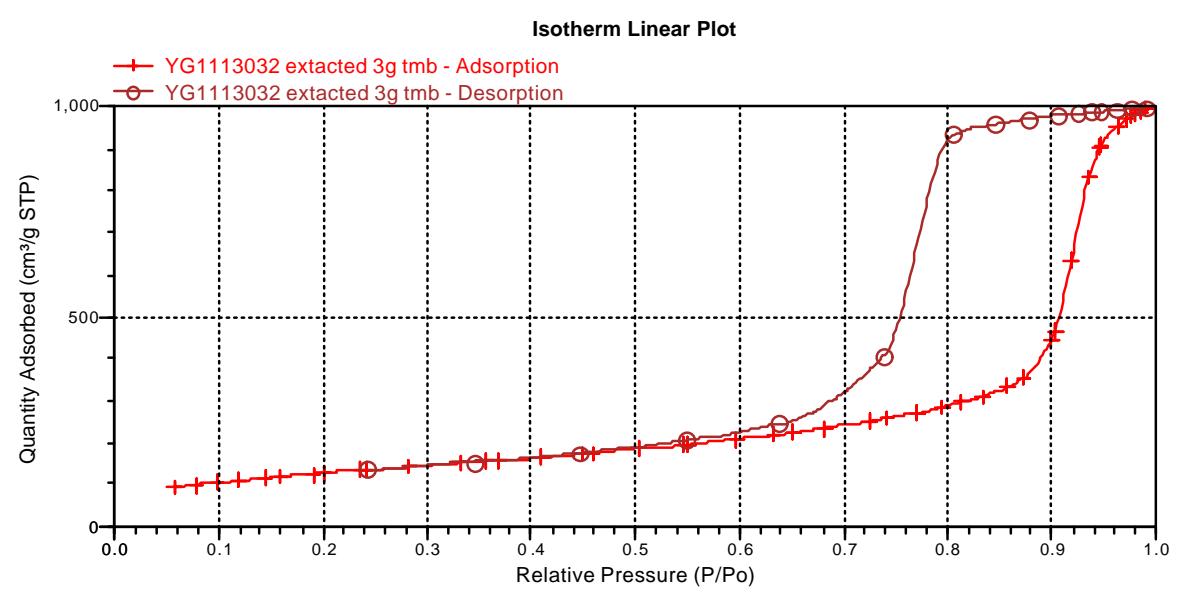

Figure 4. Adsorption-desorption isotherms of nanoporous SBA-15 synthesized in the presence of $0 \mathrm{~g} \mathrm{TMB}$ (top), $1.5 \mathrm{~g}$ (middle) and $3 \mathrm{~g}$ of TMB (bottom) in synthesis mixture.
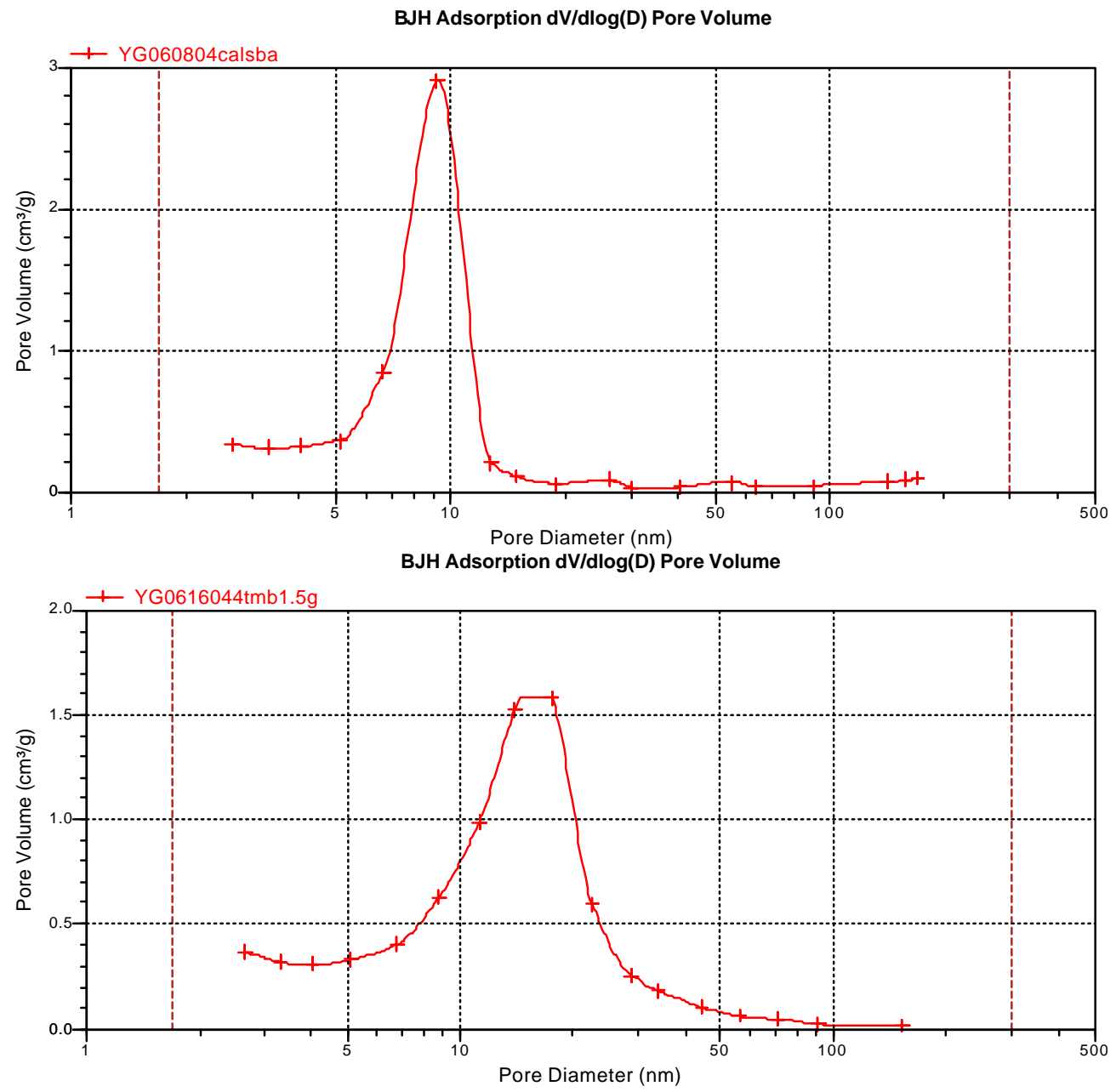


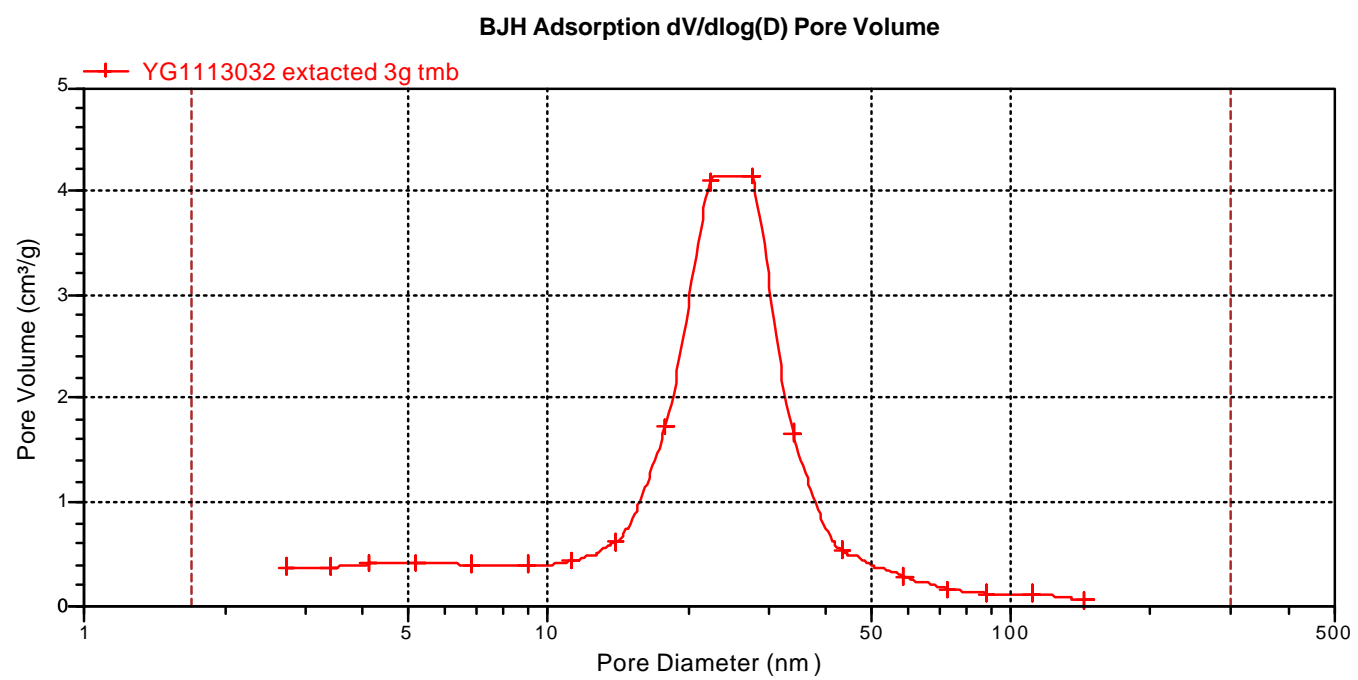

Figure 5. Pore size distribution curves of nanoporous SBA-15 synthesized with $0 \mathrm{~g}$ TMB (top), $1.5 \mathrm{~g}$ (middle) and $3 \mathrm{~g}$ of TMB (bottom) .

Figure 6 shows the X-ray diffraction of pure SBA-15 (A) synthesized in the presence of sulfuric acid, The XRD shows large peak around $1.0^{\circ}$ two theta and two smaller peaks between $1.5^{\circ}$ and $2.5^{\circ}$ two theta assigned to the (100), (110) and (200) reflections, which are consistent with occurrence of a mesophase with well-ordered hexagonal symmetry of SBA-15. This verified that SBA-15 could be prepared in the less frequently used sulfuric acid medium, instead of the traditional and widely used hydrochloric acid medium.

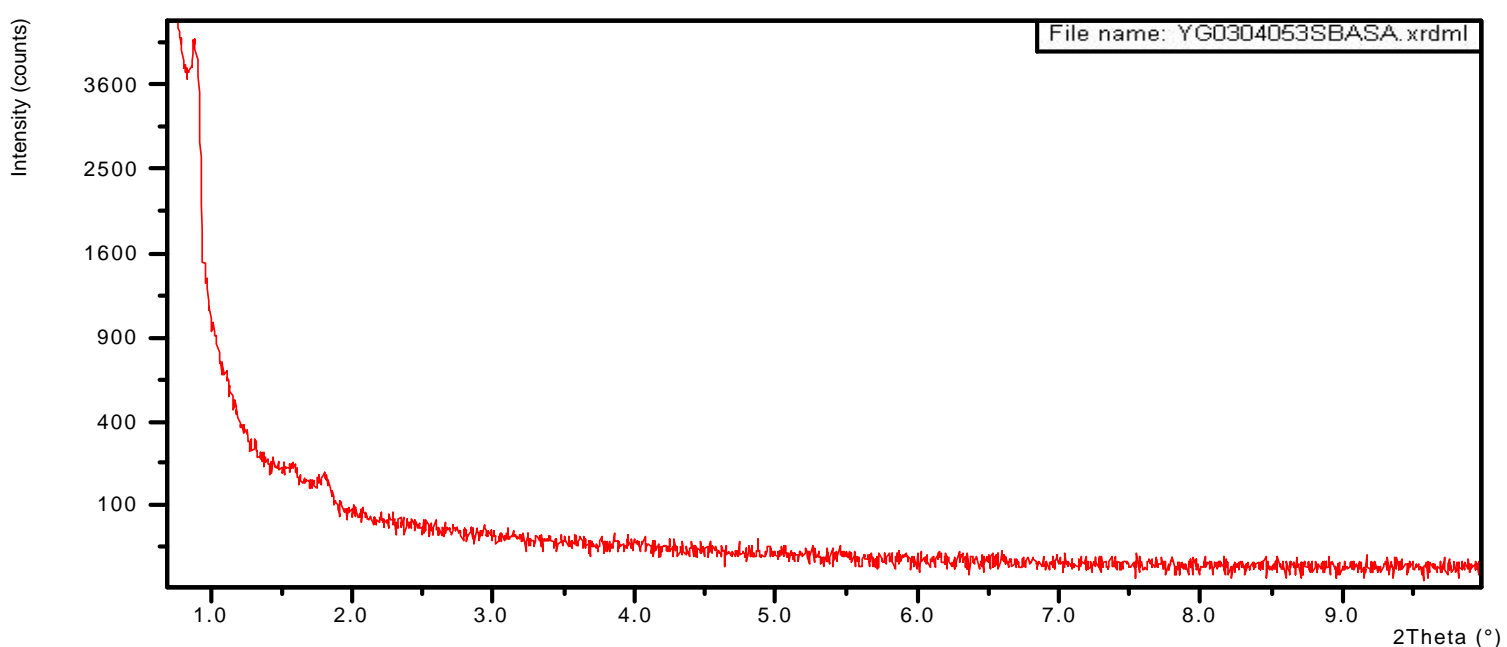

Figure 6. X-ray diffraction of pure SBA-15 in the presence of $\mathrm{H}_{2} \mathrm{SO}_{4}$ (no Zeolite Y precursor added) 
Isotherm Linear Plot

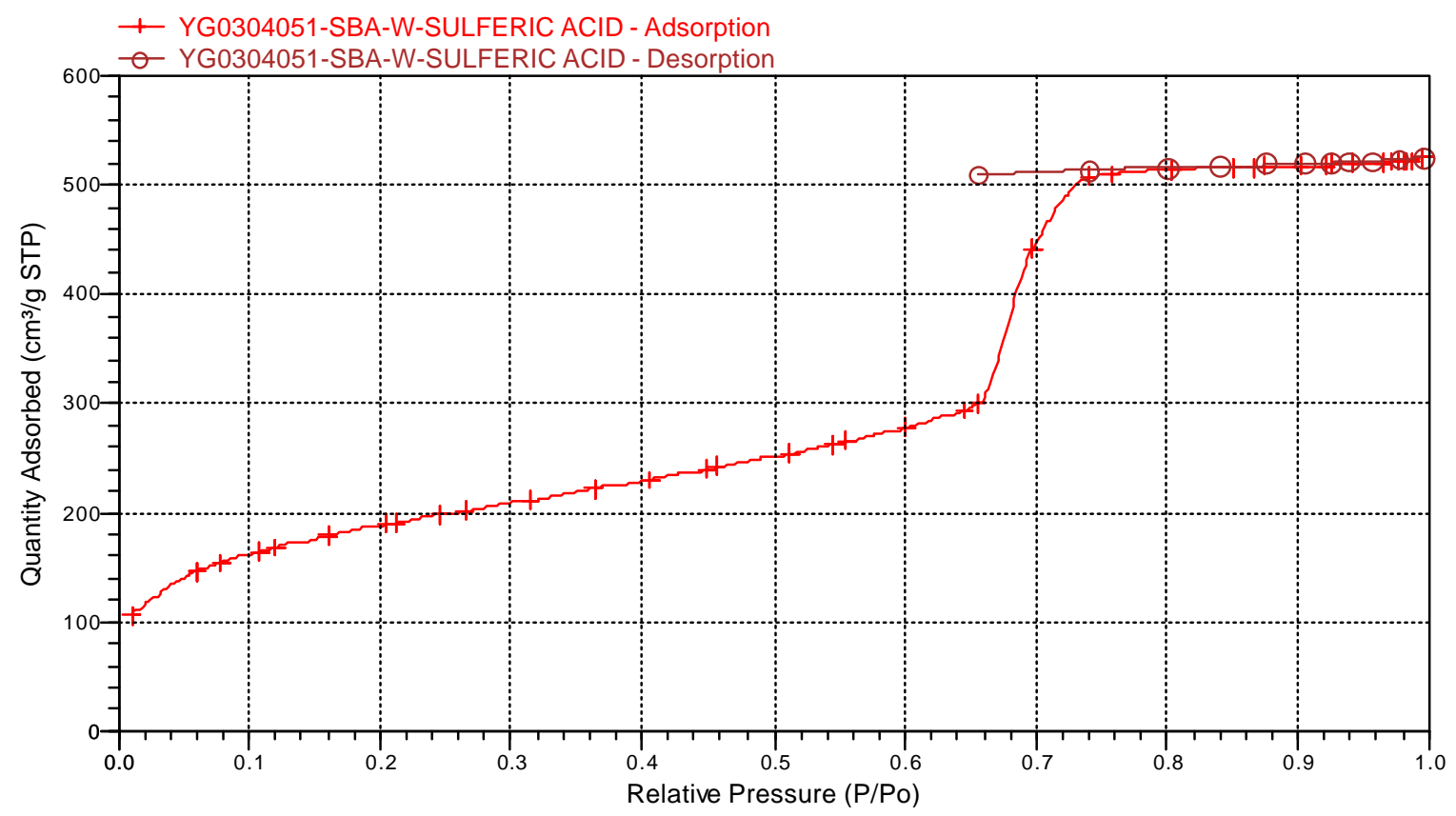

Figure 7. $\mathrm{N}_{2}$ Absorption-desorption isotherms of calcined SBA-15 synthesized in $\mathrm{H}_{2} \mathrm{SO}_{4}$

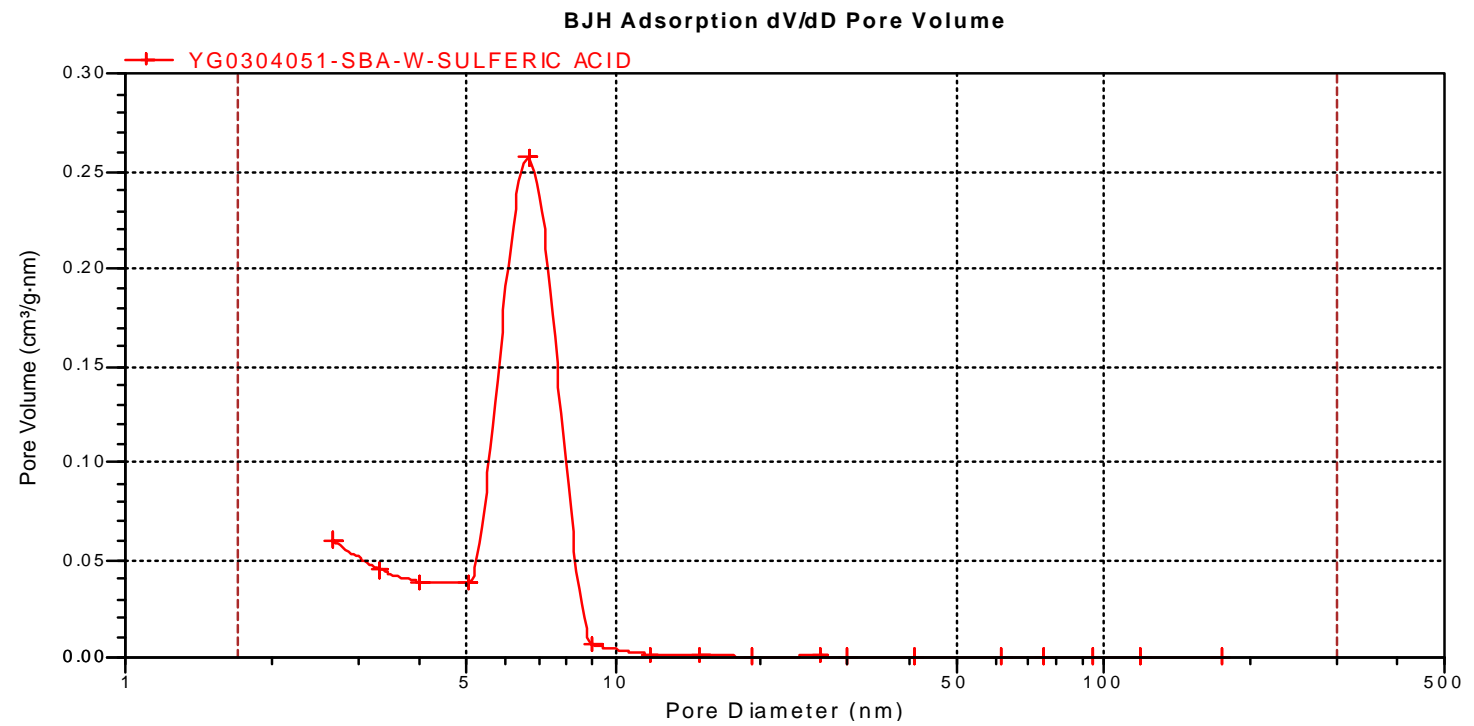

Figure 8. Pore size distribution of calcined SBA-15 synthesized in the presence of $\mathrm{H}_{2} \mathrm{SO}_{4}$

Figure 7 shows the adsorption-desorption isotherms of SBA-15 synthesized in the presence of $\mathrm{H}_{2} \mathrm{SO}_{4}$. Type IV isotherms were observed, confirming that all products were mesoporous. In the case of SBA-15, inflection corresponding to filling of mesopores commenced at relative pressures $\left(\mathrm{P} / \mathrm{P}_{\mathrm{o}}\right)$ around 0.65 during the adsorption phase. The pore size distribution of the calcined SBA-15 (from $\mathrm{H}_{2} \mathrm{SO}_{4}$ synthesis) showed surface area of $656 \mathrm{~m}^{2} / \mathrm{g}$, pore volume $0.81 \mathrm{~cm}^{3} / \mathrm{g}$ and average 
$\mathrm{BJH}$ adsorption pore diameter of $4.8 \mathrm{~nm}$ (Figure 8). These are comparable number to those obtained for SBA-15 from $\mathrm{HCl}$ synthesis above, except for the pore size which is approximately half.

\section{VI-2 Comparison of Synthesis of Standard Zeolite Y and Zeolite Y Nanoparticles}

Figure 9 shows the diffraction pattern of the zeolite $\mathrm{Y}$ synthesized (according to the method Ginter et. $\mathrm{al}^{2}$ ) for comparison purposes. The first 5 reflections at 2 angles of $7.14^{\circ}, 10.1^{\circ}, 12.4^{\circ}$, $16.1^{\circ}$ and $20.4^{\circ}$ are characteristic of zeolite $Y^{2,3}$ The low background and strong reflections indicate that the sample is highly crystalline.

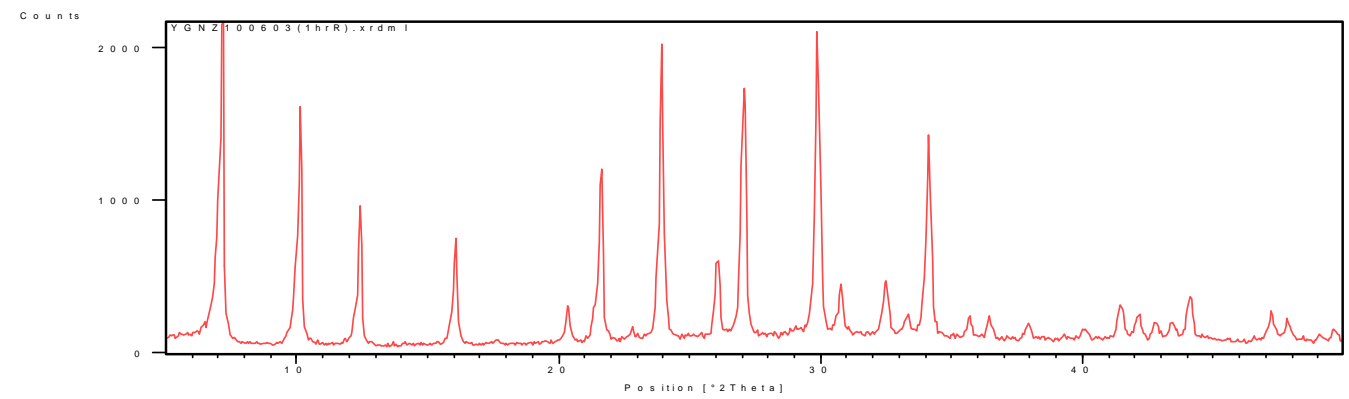

Figure 9 XRD of standard zeolite Y synthesized in the absence of TMA cations 


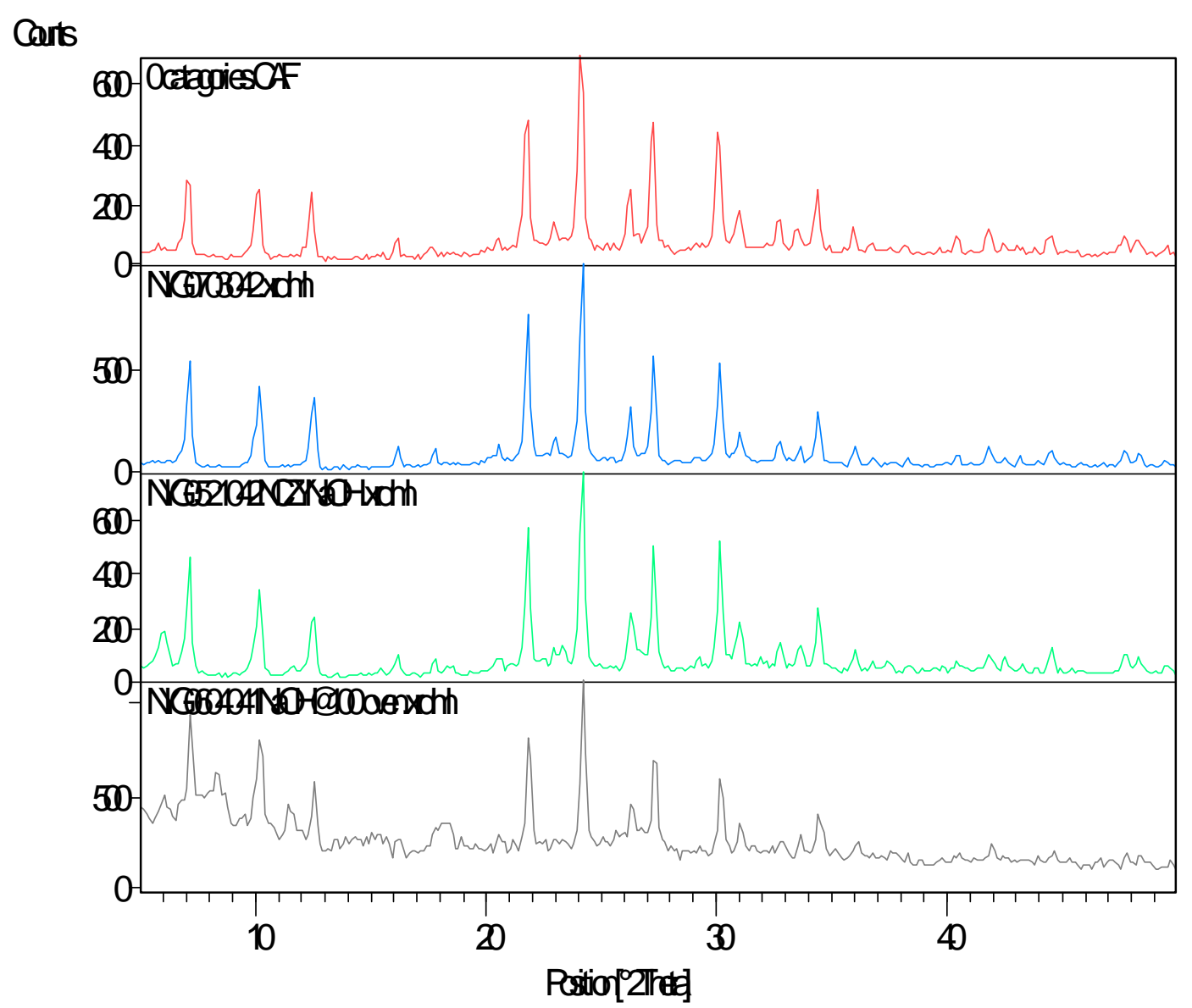

Figure 10. XRD Diffraction patterns of zeolite $\mathrm{Y}$ synthesized in the presence of TMAOH at $100^{\circ} \mathrm{C}$ for various times ( $45 \mathrm{hrs}$ to $168 \mathrm{hr}$ from top to bottom).

Figure 10 shows $\mathrm{XRD}$ patterns of zeolite $\mathrm{Y}$ synthesized in the presence of $\mathrm{TMAOH}$ at $100^{\circ} \mathrm{C}$ at various crystallization times ( $45 \mathrm{~h}$ to $168 \mathrm{~h}$ from top to bottom). No significant differences were observed between the patterns, suggesting that zeolite $\mathrm{Y}$ crystals are formed as early as $45 \mathrm{~h}$ at $100^{\circ} \mathrm{C}$ in the presence of TMAOH.

In contrast to Figures 9 and 10, Figures 11 and 12 shows XRD patterns for samples obtained when TMABr was added to the TMAOH-containing mixtures. For both figures, XRD analysis shows that highly crystalline zeolite $\mathrm{Y}$ products were obtained in the presence of $\mathrm{TMABr}$, but a sharp peak at 2 angle around $23^{\circ}$ is predominant in all patterns. This peak became more predominant as the concentration of TMABr was increased (Figure 10) and is possibly due to the precipitation/recrystallization of the TMABr salt within the pores of the zeolite. 


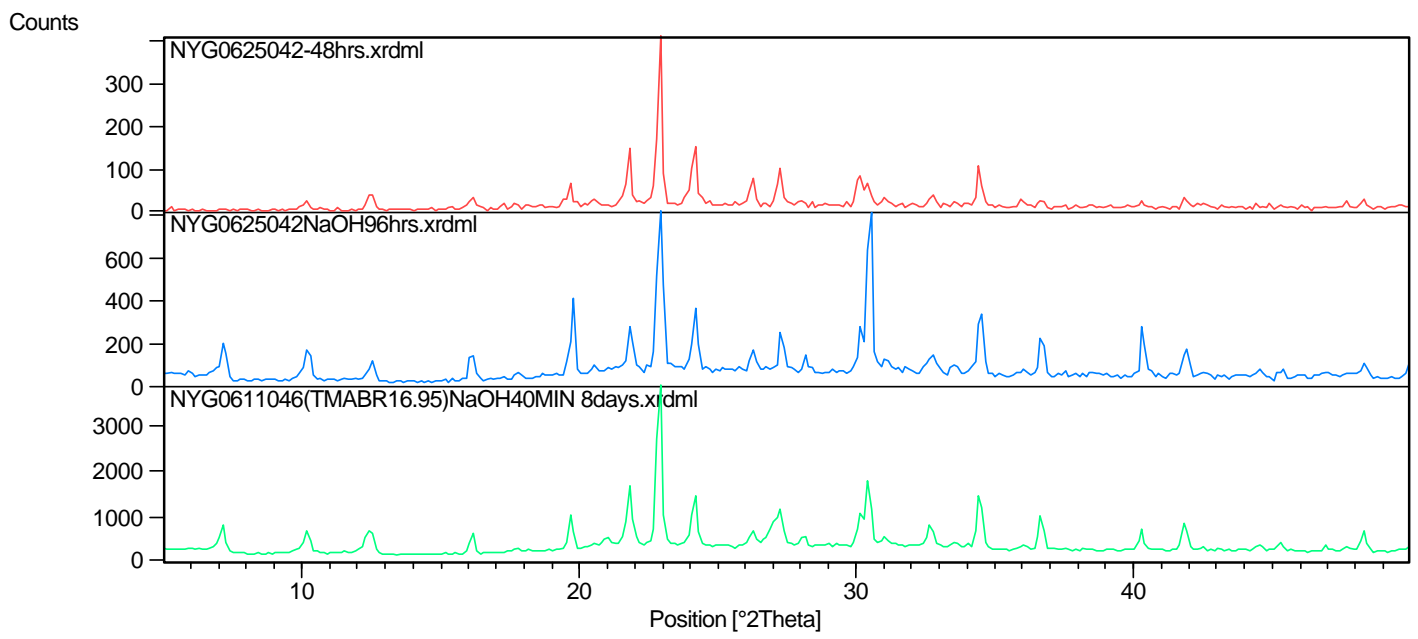

Figure 11. XRD patterns of zeolite $Y$ samples synthesized in the presence of $\mathrm{TMABr} / \mathrm{OH}$ ( $\mathrm{TMABr} / \mathrm{OH}$ ratio $=0.64$ ) with increasing synthesis time up to eight days.

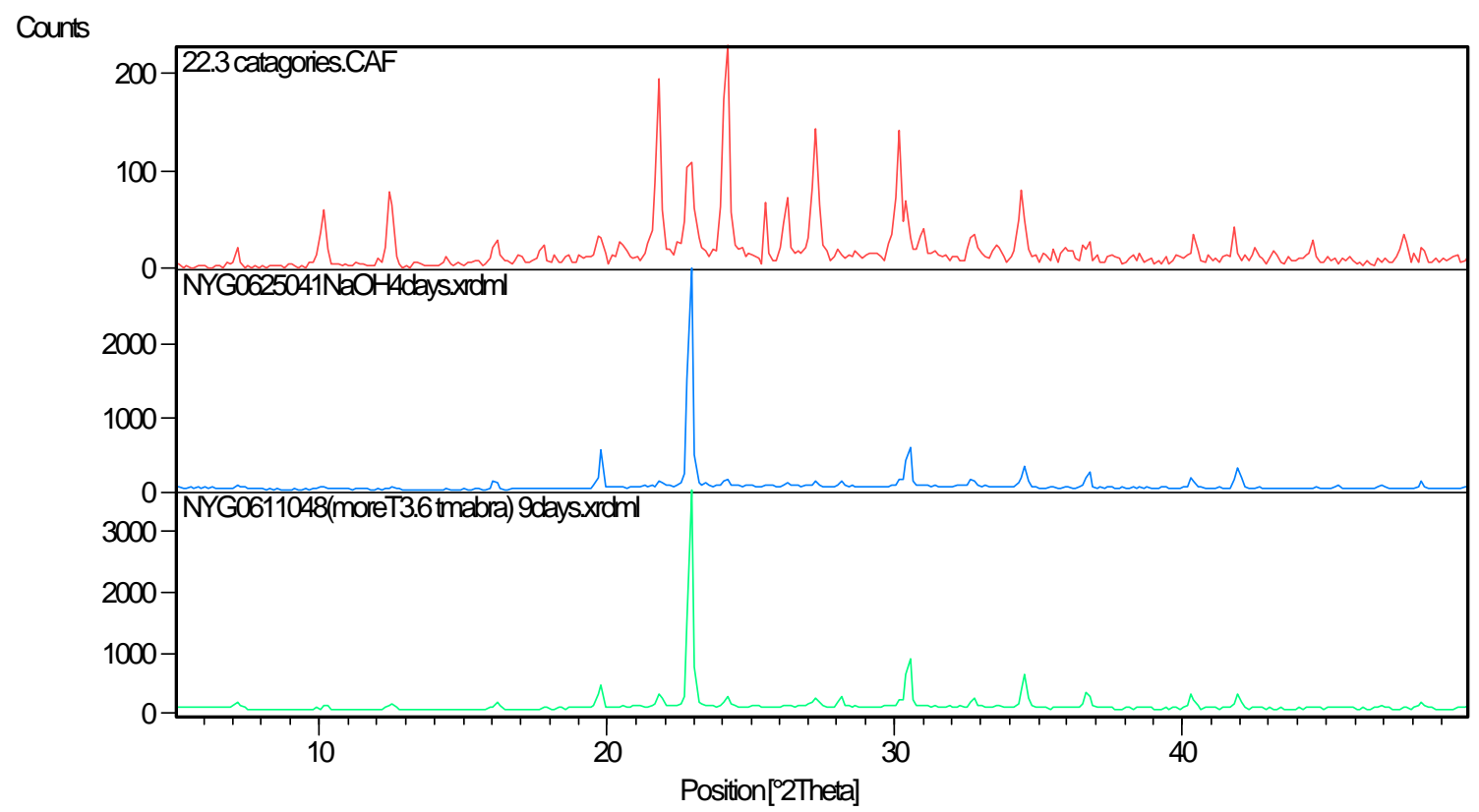

Figure 12. XRD Patterns of zeolite $Y$ samples synthesized in the presence of $\mathrm{TMABr} / \mathrm{OH}$ $(\mathrm{TMABr} / \mathrm{OH}$ ratio $=1.07)$ with increasing synthesis time up to nine days.

The impact TMAOH and TMABr can be observed in the particle size distribution of the resulting zeolite Y products. Dynamic light scattering results (Figure 13) show that the particles size of zeolite Y synthesis under standard conditions and in the absence of organics, ranged from 100 to $1000 \mathrm{~nm}$ with a median of $284 \mathrm{~nm}$ and mean of $267 \mathrm{~nm}$. However, zeolite Y synthesized in the presence of TMAOH under conditions defined above are of median sizes around $75 \mathrm{~nm}$ after 4 to 
7 days at $100^{\circ} \mathrm{C}$ (Figures 14). The morphology of these particles as obtained by AFM is show in Figure 13. At longer crystallization time (up to $196 \mathrm{~h}$ ) particle size increased to approximately 80 nm (Figure 13).

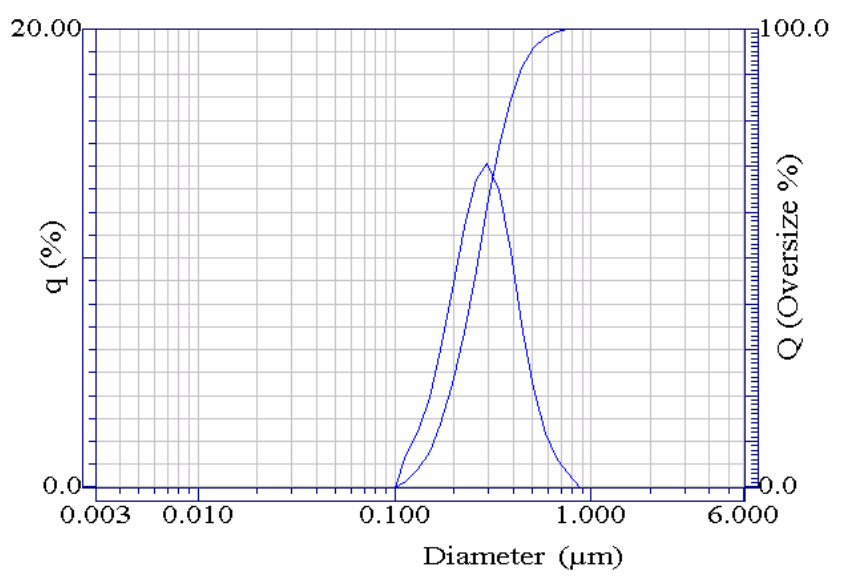

Figure 13. DLS particle size distribution of zeolite Y synthesized in the absence of TMA cation.

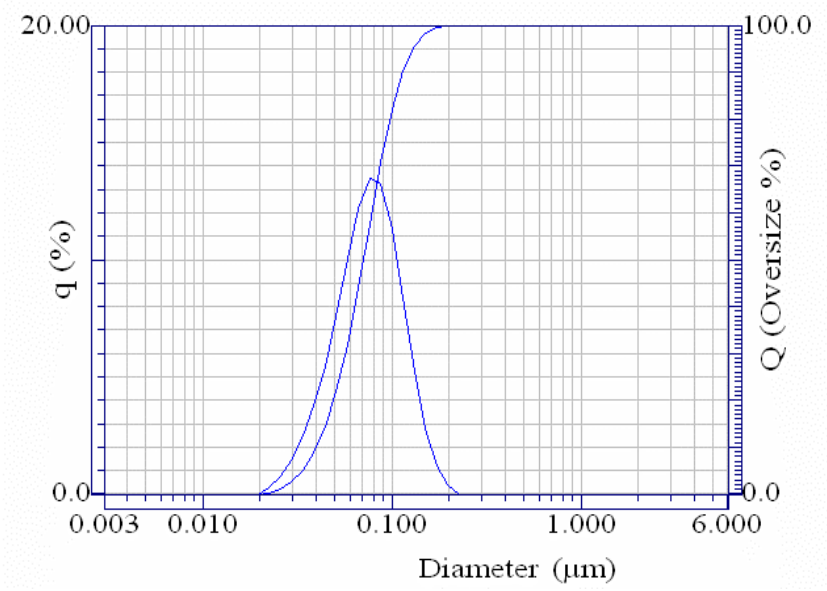

Figure 14. DLS particle size distribution of zeolite Y synthesized in the presence of TMAOH. 


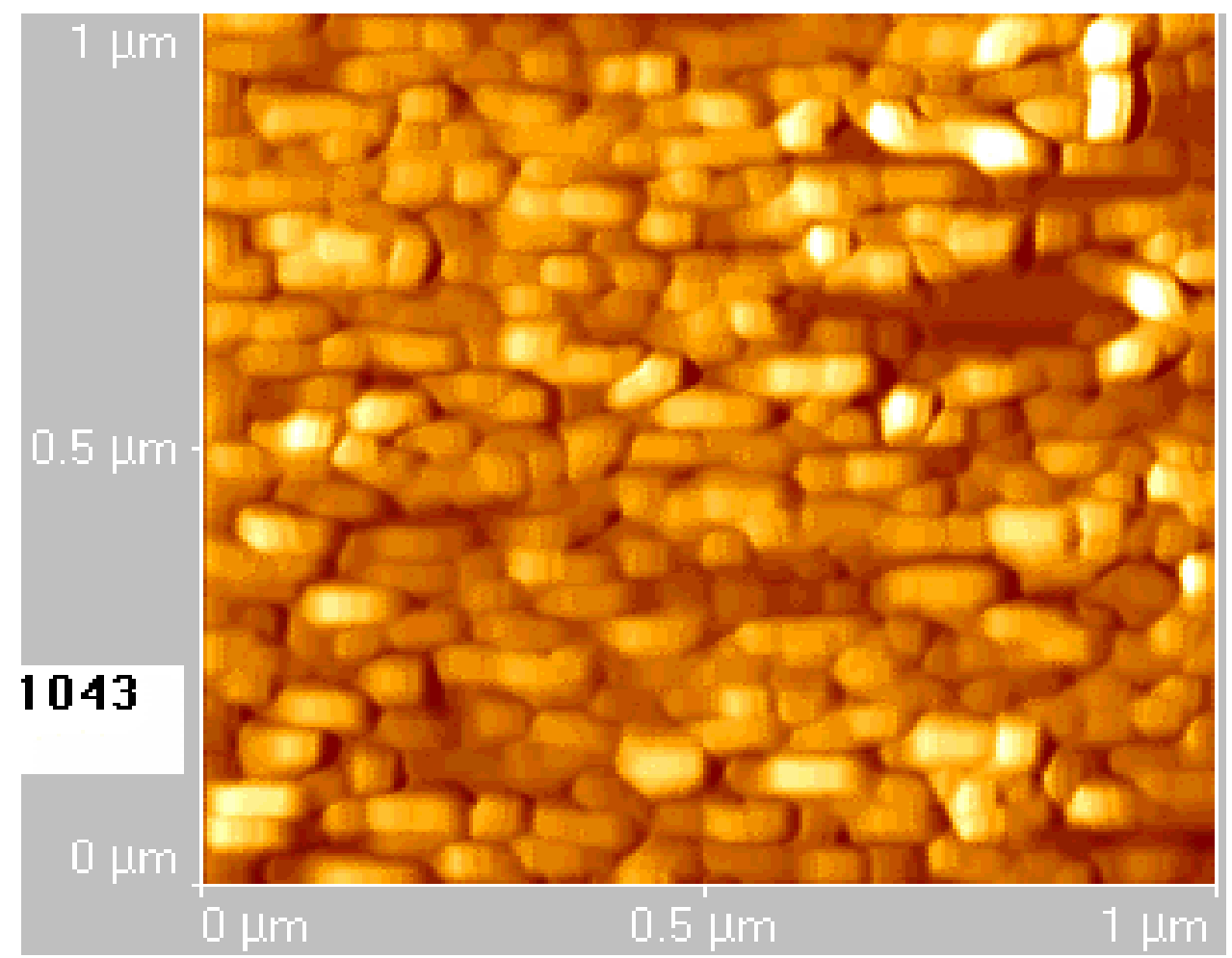

Figure 15. AFM scan showing morphology of zeolite Y synthesized in the presence of TMAOH 


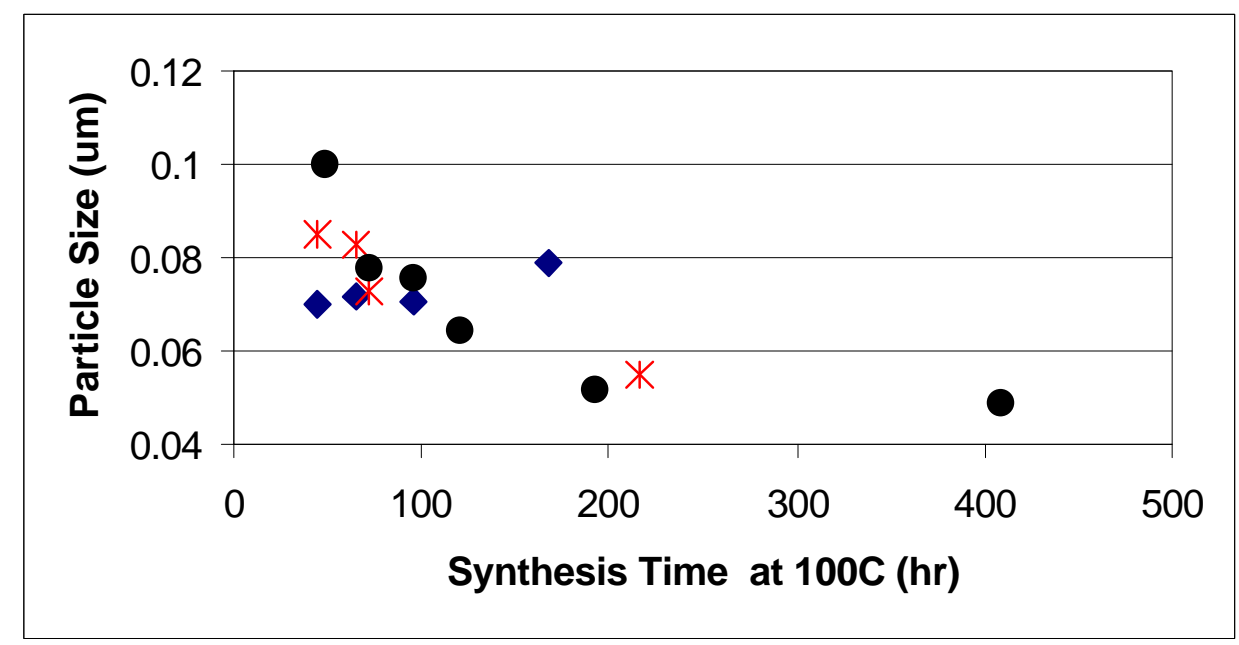

Figure 16. Median particle size of Zeolite $\mathrm{Y}$ nanocrystals as a function of synthesis time and with increasing concentration of TMABr $(\diamond-0 \mathrm{TMABr}, \cdot-\mathrm{TMABr} / \mathrm{TMAOH}=0.64, *-\mathrm{TMABr} /$ $\mathrm{TMAOH}=1.07)$.

In the presence of $\mathrm{TMABr}$ however, particle size decreased with increase in synthesis time (Figure 16). After $196 \mathrm{~h}$ at $100^{\circ} \mathrm{C}$, the median particle size obtained in the TMABr/ TMAOH system (of mole ratio 0.64) was approximately $55 \mathrm{~nm}$. Increasing the TMABr to TMABr/ TMAOH molar ratio of 1.07 showed no additional decrease in particle size of the zeolite, but XRD patterns of products obtained form the presence of additional TMABr show sharp peaks around 2 angle of $23^{\circ}$ mentioned earlier (Figures 9 and 10) which is assumed to have resulted from the precipitation of crystalline TMABr salt. On calcination of one of these samples at $400^{\circ} \mathrm{C}$, the peak disappeared (Figure 17) possibly as a result of thermal decomposition of the salt. Higher background in the XRD of the calcined sample in comparison to its as-synthesized parent, suggests that zeolite Y looses some crystallinity during the calcinations process. 


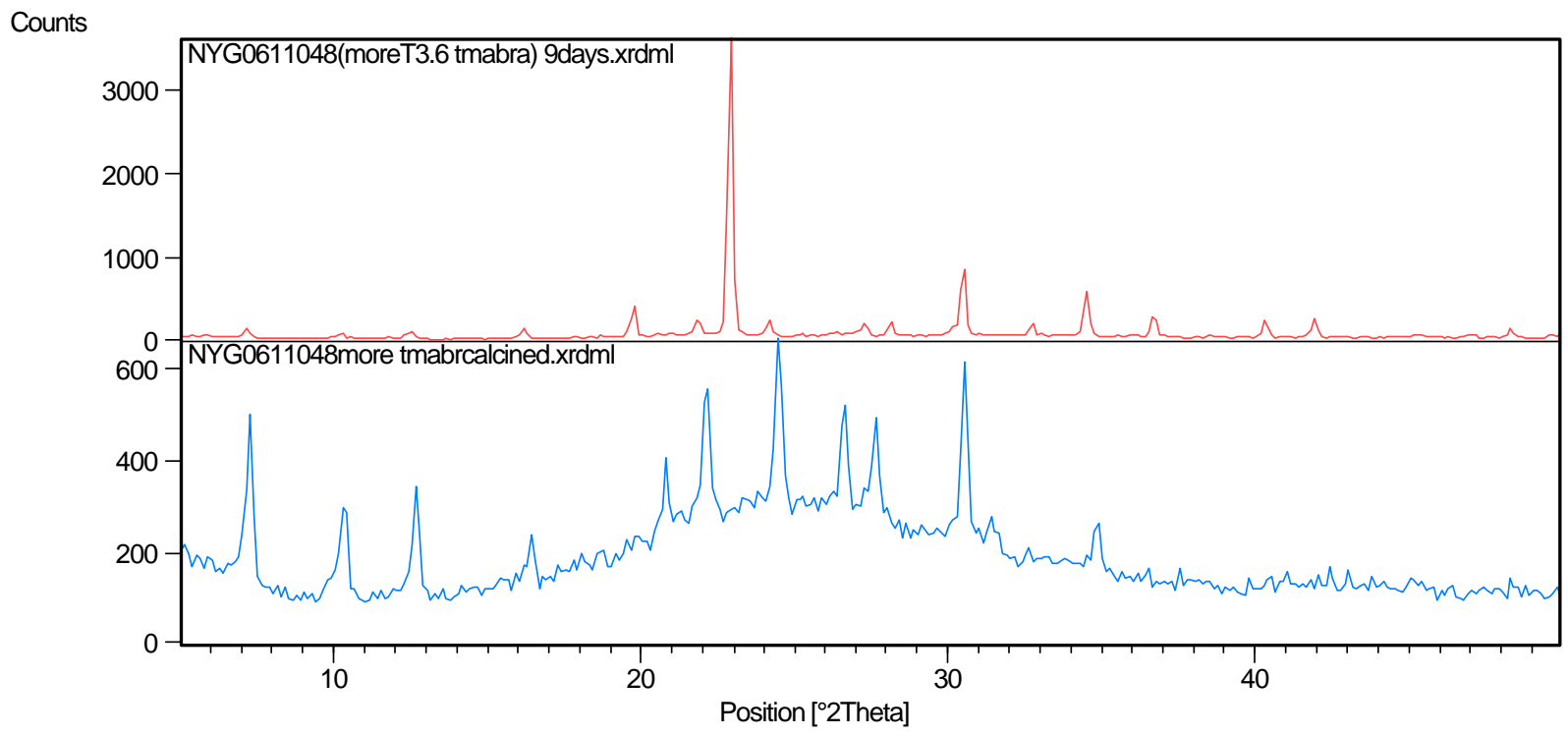

Figure 17. XRD pattern of "as-synthesized" (top) and calcined (bottom) zeolite Y nanocrystals synthesized in the presence of TMAOH/TMABr system (TMABr/ TMAOH $=1.07$ ).

\section{VI-3 Synthesis of Zeolite Y/SBA-15 composites}

In this section we describe our research progress on the synthesis of zeolite Y/SBA-15 composites by first aging zeolite Y precursor mixtures and subsequently modified the chemical composition of the mixtures and other synthesis parameters to allow SBA-15 or related mesoporous phase to crystallize.

X-Ray Diffraction Analysis: XRDs of zeolite Y/SBA-15B composite (with zeolite Y seeds aged $100^{\circ} \mathrm{C}$ for $6 \mathrm{hrs}$ ), (Figure 18 ), and Zeolite Y/SBA-15B (with zeolite Y seeds aged at $100^{\circ} \mathrm{C}$ for 3 days), (Figure 19), each show a broad peak at two theta value around $1.5^{\circ}$. Smaller peaks at higher angles $\left(1^{\circ}\right.$ to $\left.2^{\circ}\right)$ were not observed, possible because they were obscured by the broad peak. The broad peak and absence of the smaller peaks in each diffractogram suggest the presence of disordered mesostructured phase in each. From repeated experiments described above, we have observed (using dynamic light scattering measurements) that heated zeolite Y precursor mixtures yielded nanocrystallites of zeolite $\mathrm{Y}$ after aging for $6 \mathrm{hr}$ at $100^{\circ} \mathrm{C}$. It is possible therefore, that nanocrystals of zeolite $\mathrm{Y}$ could be trapped within the pores of SBA-15 mesophase (or the 
mesopores of SBA-15 could have organized themselves around the smaller crystallites of zeolite Y).

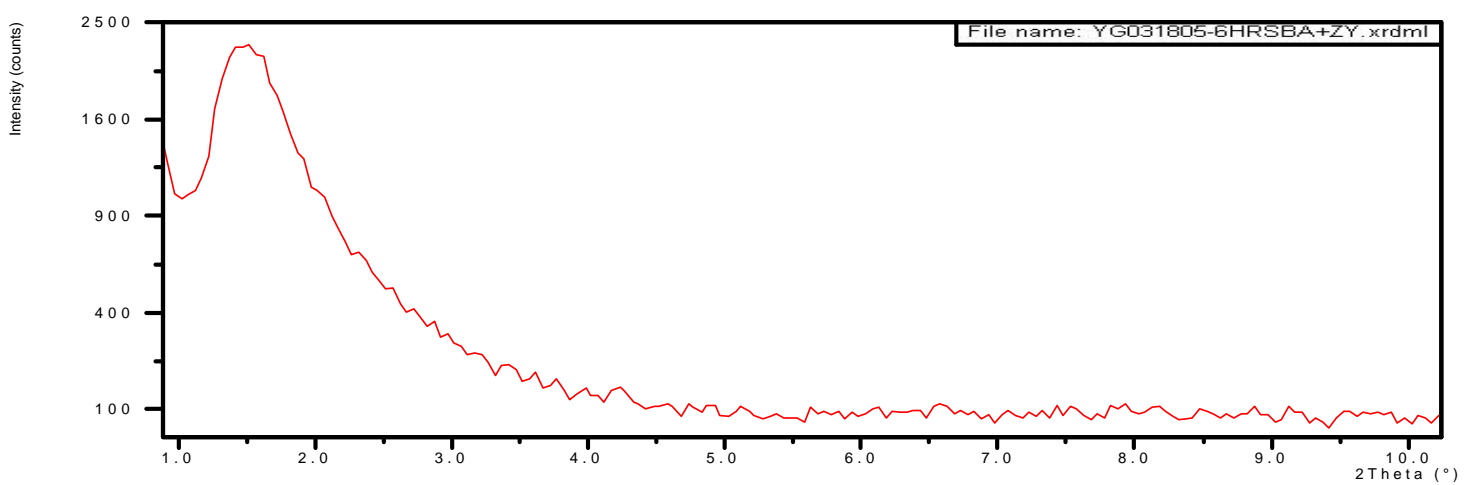

Figure 18. X-ray diffraction of zeoliteY/SBA-15B composite (with zeolite Y seeds aged at RT plus $100^{\circ} \mathrm{C}$ for $6 \mathrm{hrs}$ )

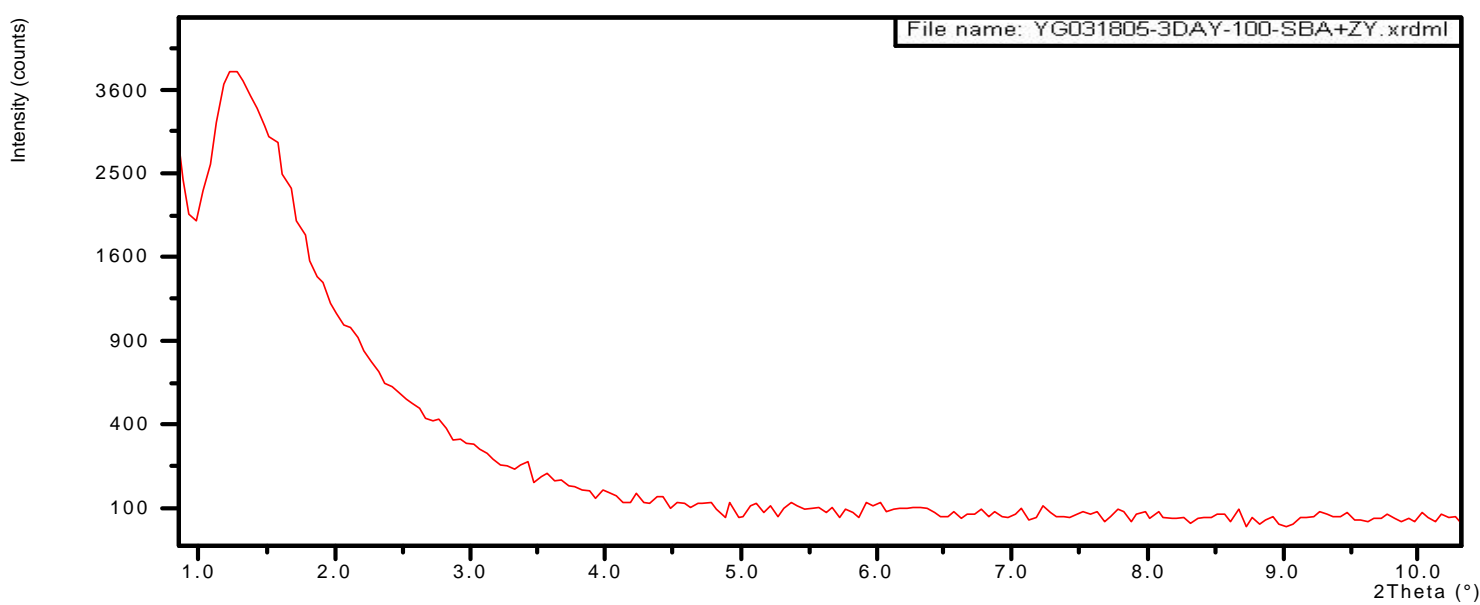

Figure 19. X-ray diffraction of zeolite $\mathrm{Y} / \mathrm{SBA}-15 \mathrm{C}$ composite (with zeolite $\mathrm{Y}$ seeds aged at RT plus $100^{\circ} \mathrm{C}$ for 3 days hrs)

Porosimetry and Surface Area analysis: Figures 20 and 21 show the adsorption-desorption isotherms of (B) zeoliteY/SBA-15B composite (with zeolite $\mathrm{Y}$ seeds aged at RT plus $100^{\circ} \mathrm{C}$ for $6 \mathrm{hrs}$, and (C) zeoliteY/SBA-15B composite (with zeolite Y seeds aged at RT plus $100^{\circ} \mathrm{C}$ for 3 days) respectively. Type IV isotherms were observed in all, confirming that all products were mesoporous. In the case of SBA-15, inflection corresponding to filling of mesopores commenced at relative pressures $\left(\mathrm{P} / \mathrm{P}_{\mathrm{o}}\right)$ around 0.65 during the adsorption phase. In the case of the composite materials, filling of mesopores commenced at higher P/Po, 0.7 for zeoliteY/SBA-15B, and 0.8 for 
zeoliteY/SBA-15C suggesting a correlation between zeolite Y precursor aging and pore size of the resulting mesophase.

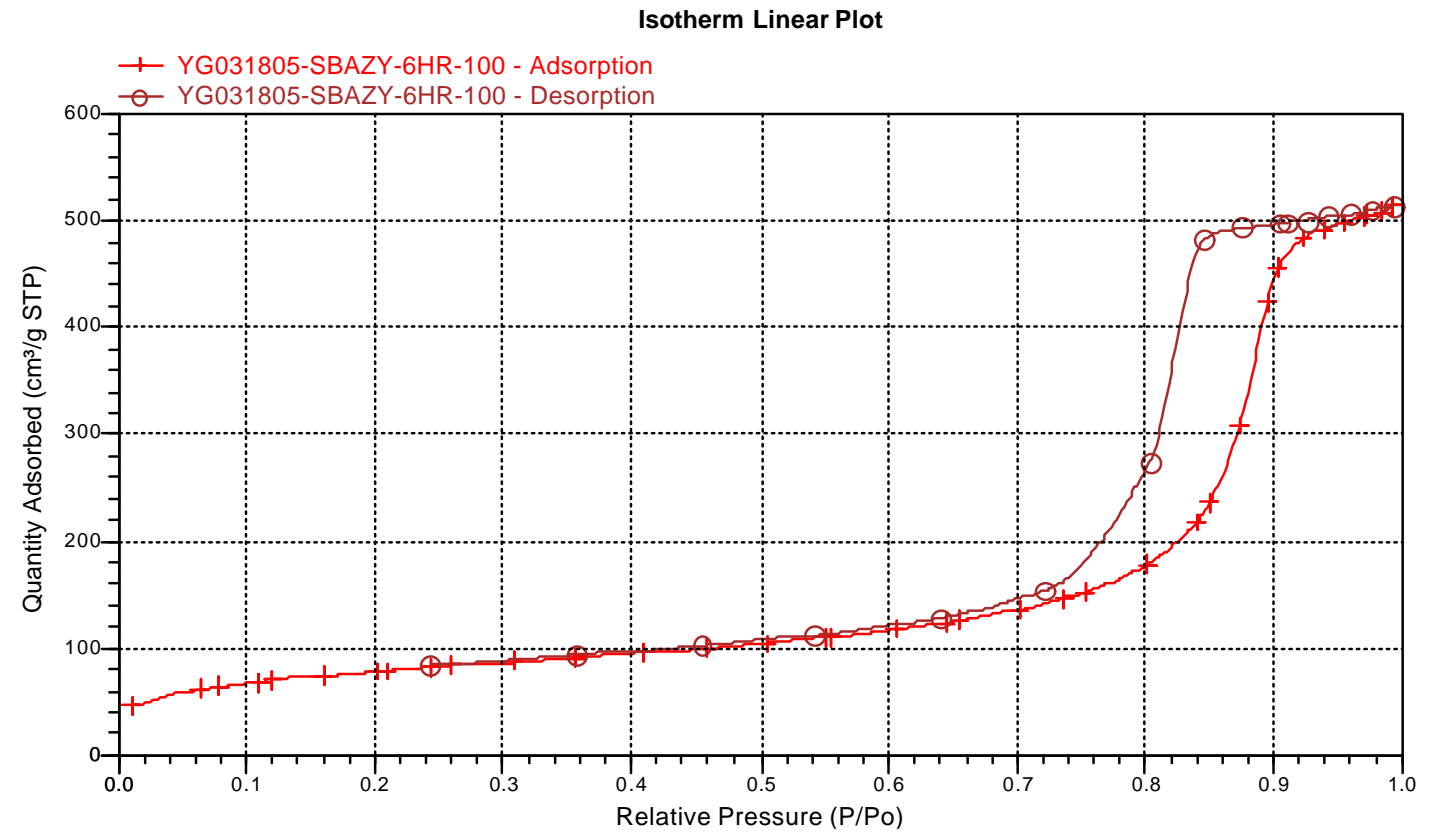

Figure 20. $\mathrm{N}_{2}$ Absorption-desorption isotherms of calcined of Y/SBA-15B composite synthesized form zeolite Y precursor aged at RT plus $100^{\circ} \mathrm{C}$ for $6 \mathrm{hrs}$ Isotherm Linear Plot

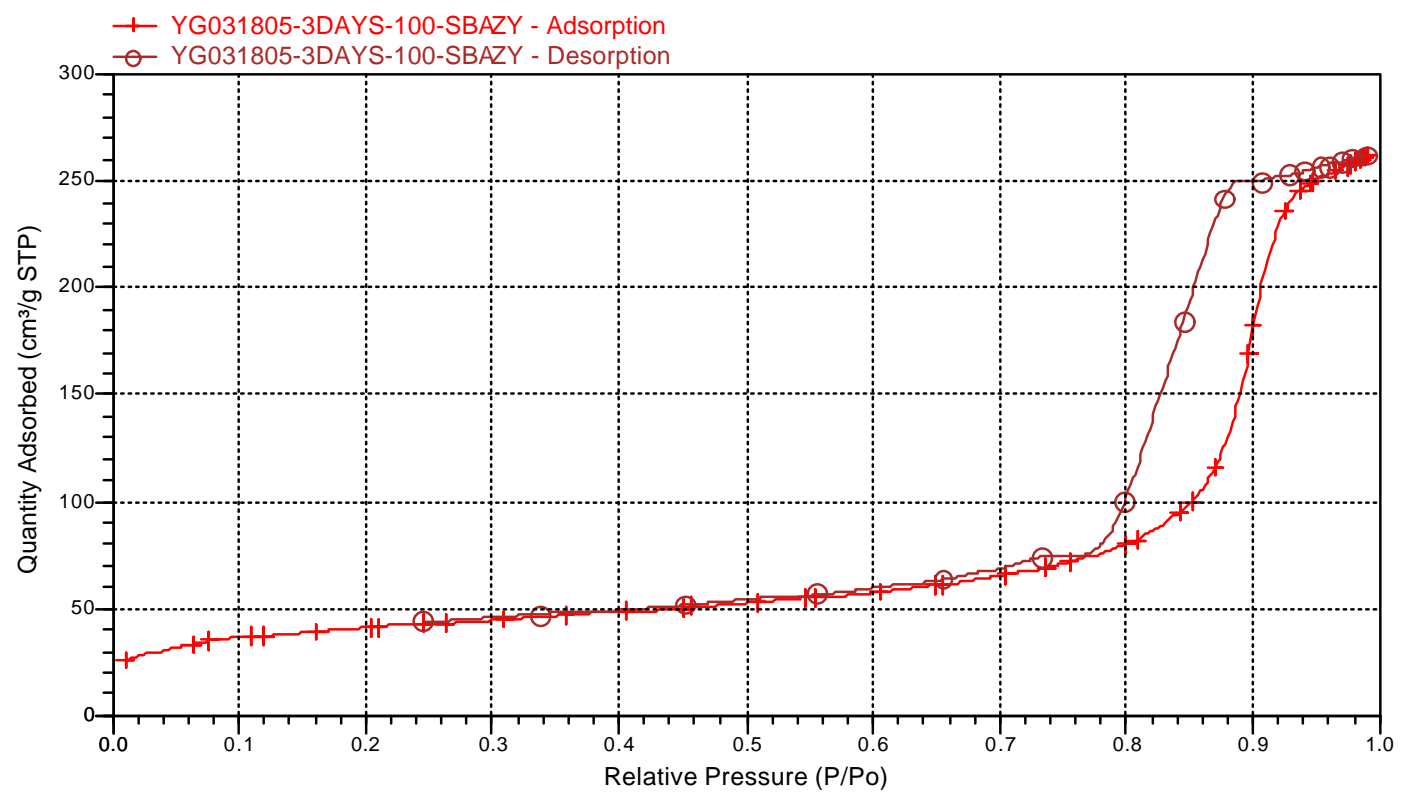

Figure 21. $\mathrm{N}_{2}$ Absorption-desorption isotherms of calcined zeolite Y/SBA-15C nanocomposite synthesized from zeolite $\mathrm{Y}$ precursor aged at RT plus 3 days and at $100^{\circ} \mathrm{C}$ for 3 dys. 


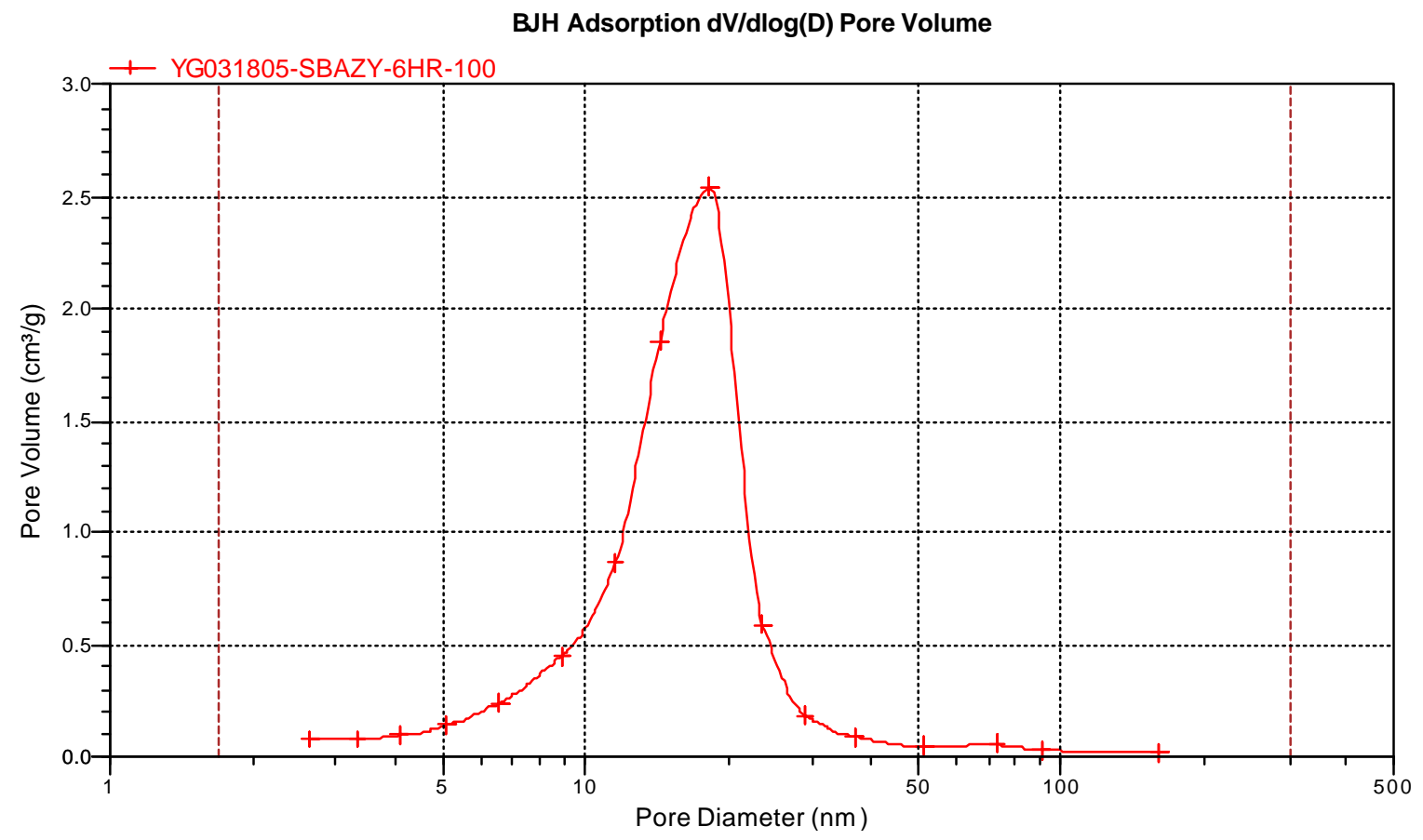

Figure 22. Pore size distribution of calcined Zeolite Y/SBA-15B nanocomposite synthesized from zeolite Y precursor which was aged at room temperature for 3 days and at $100^{\circ} \mathrm{C}$ for $6 \mathrm{hr}$.

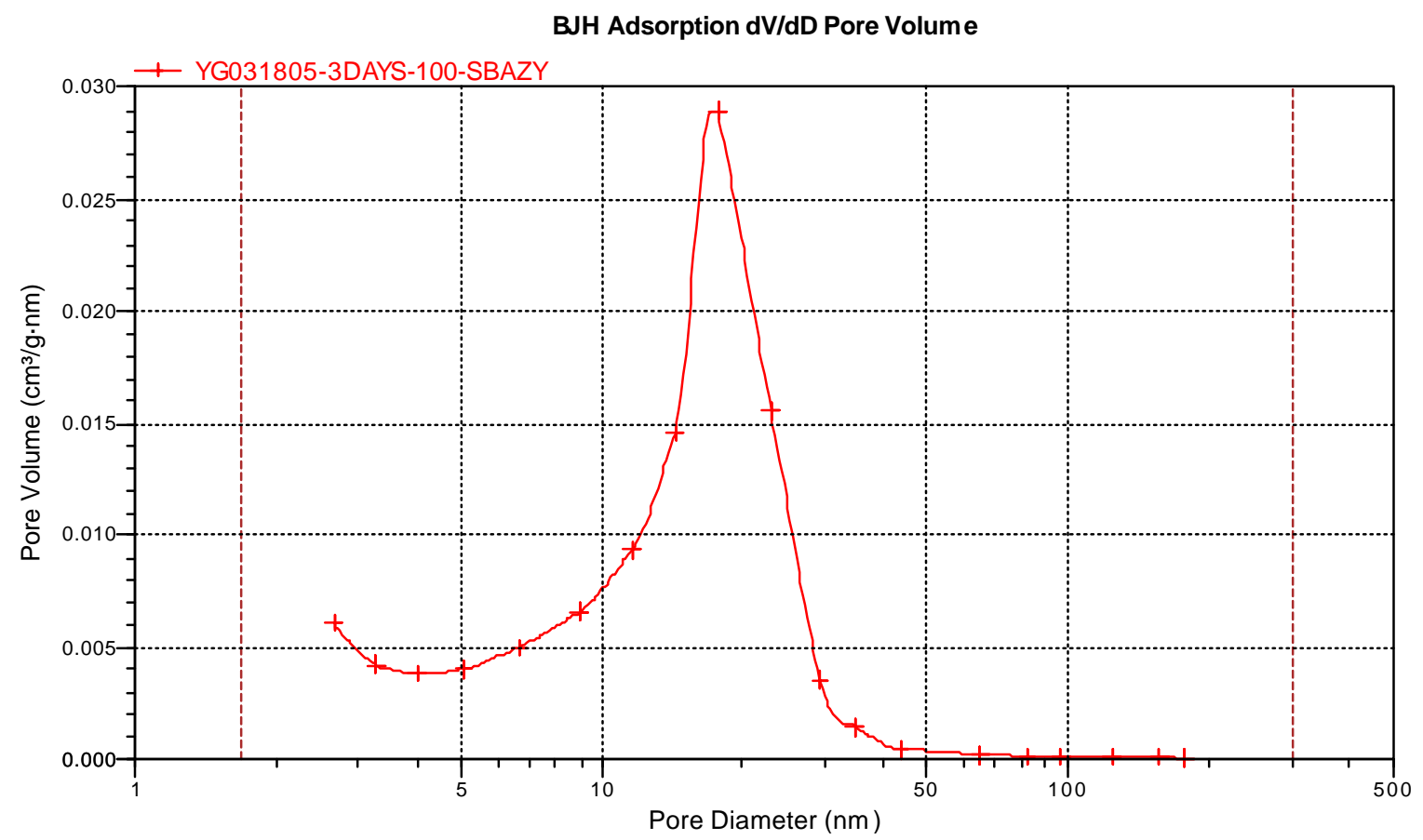

Figure 23. Pore size distribution of calcined Zeolite Y/SBA-15C nanocomposite synthesized from zeolite $\mathrm{Y}$ precursor which was aged at room temperature for 3 days and at $100^{\circ} \mathrm{C}$ for 3 days. 
Table 1. Pore sizes distribution and surface areas of SBA-15 and Zeolite Y/SBA-15 composites

\begin{tabular}{|l|c|c|c|}
\hline Sample ID & $\begin{array}{l}\text { Time in } \\
\text { days at } \\
100^{\circ} \mathrm{C}\end{array}$ & Surface area in $\mathrm{m}^{2} / \mathrm{g}$ & Pore size (nm) \\
\hline $\begin{array}{l}\text { Pure SBA-15 from } \\
\mathrm{H}_{2} \mathrm{SO}_{4}\end{array}$ & 2 & 653 & 4.8 \\
\hline $\begin{array}{l}\text { Zeolite Y/SBA-15 } \\
\text { YG031805-RT }\end{array}$ & 0 & 158 & 11.3 \\
\hline $\begin{array}{l}\text { Zeolite Y/SBA-15B } \\
\text { YG031805-6hrs }\end{array}$ & 0.25 & 271 & 11.3 \\
\hline $\begin{array}{l}\text { Zeolite Y/SBA-15 } \\
\text { YG031805-1day }\end{array}$ & 1 & 239 & 14.1 \\
\hline $\begin{array}{l}\text { Zeolite Y/SBA-15C } \\
\text { YG031805-3day }\end{array}$ & 3 & 142 & 11.2 \\
\hline $\begin{array}{l}\text { Zeolite Y/SBA-15 } \\
\text { YG031805-4days }\end{array}$ & 4 & 242 & 11.7 \\
\hline
\end{tabular}

Pore size distribution and surface area analysis of calcined zeolite Y/SBA-15B, nanocomposite synthesized from zeolite Y precursor which was aged at room temperature for $6 \mathrm{hr}$ (Figure 22 and Table 1) showed surface area of $271 \mathrm{~m}^{2} / \mathrm{g}$, BJH adsorption pore volume of $0.79 \mathrm{~cm}^{3} / \mathrm{g}$, and pore size of $11.3 \mathrm{~nm}$. Calcined zeolite Y/SBA-15C nanocomposite synthesized from zeolite $\mathrm{Y}$ precursor which was aged at room temperature for 3 days and at $100^{\circ} \mathrm{C}$ for 3 days (Figure 23 and Table 1) showed surface area of $142 \mathrm{~m}^{2} / \mathrm{g}$, adsorption total pore volume of pores of $0.40 \mathrm{~cm}^{3} / \mathrm{g}$, and $\mathrm{BJH}$ adsorption average pore width $11.1 \mathrm{~nm}$.

FTIR Spectra comparing zeolite Y, SBA-15 and zeolite Y/SBA-15 composite: Figure 24 shows IR spectra of several samples. The IR spectra of pure zeolite $Y\left(2^{\text {nd }}\right.$ from top left), zeolite Y/SBA-15B and zeolite Y/SBA-15C composites $\left(1^{\text {st }}\right.$ and $3^{\text {rd }}$ spectra from top left $)$ all contain bands at 570 and $470 \mathrm{~cm}^{-1}$. The band at $470 \mathrm{~cm}^{-1}$ is assigned to the structure insensitive T-O bending modes for tetrahedral $\mathrm{TO}_{4}$ units $(\mathrm{T}=\mathrm{Si}$ or $\mathrm{Al})$. The band at $570 \mathrm{~cm}^{-1}$ is attributed to the double ring external linkage associated with the $\mathrm{FAU}^{4}$ and other zeolitic structures such as MFI. ${ }^{5}$ Both peaks are present in all samples, with varying intensities. A potentially rational conclusion is that zeolite $\mathrm{Y}$ is present in the material. However, the $570 \mathrm{~cm}^{-1}$ peak is also observed in the pure 
SBA-15 sample ( $4^{\text {th }}$ spectra from top left), though to a much smaller extent, thus make it impossible to assign this peak exclusively to zeolite $\mathrm{Y}$, and to conclusively confirm the present of the zeolite, within the SBA-15 matrix. This was similarly observed by Carr $e t$. al. in their attempts to synthesize MFI-SBA-15 composite materials. ${ }^{6}$ The $570 \mathrm{~cm}^{-1}$ peak in SBA-15 is not assigned, since this material contains no double six membered rings. However from a visual inspection, it can be seen that the $570 / 470 \mathrm{~cm}^{-1}$ peak height ratio is much higher for Zeolite Y/SBA-15C composite synthesized from seeds heated at $100^{\circ} \mathrm{C}$ for three days, compared with the ratios for pure SBA-15, zeolite-Y/SBA-15 A (with zeolite $\mathrm{Y}$ seeds preheated at $100^{\circ} \mathrm{C}$ for $6 \mathrm{hrs}$ ) or for Zeolite Y/SBA-15B (with zeolite Y seeds kept at room temperature for three days). Further characterization, such as acid catalyzed reactions are being conducted to further investigate the presence of zeolite Y.

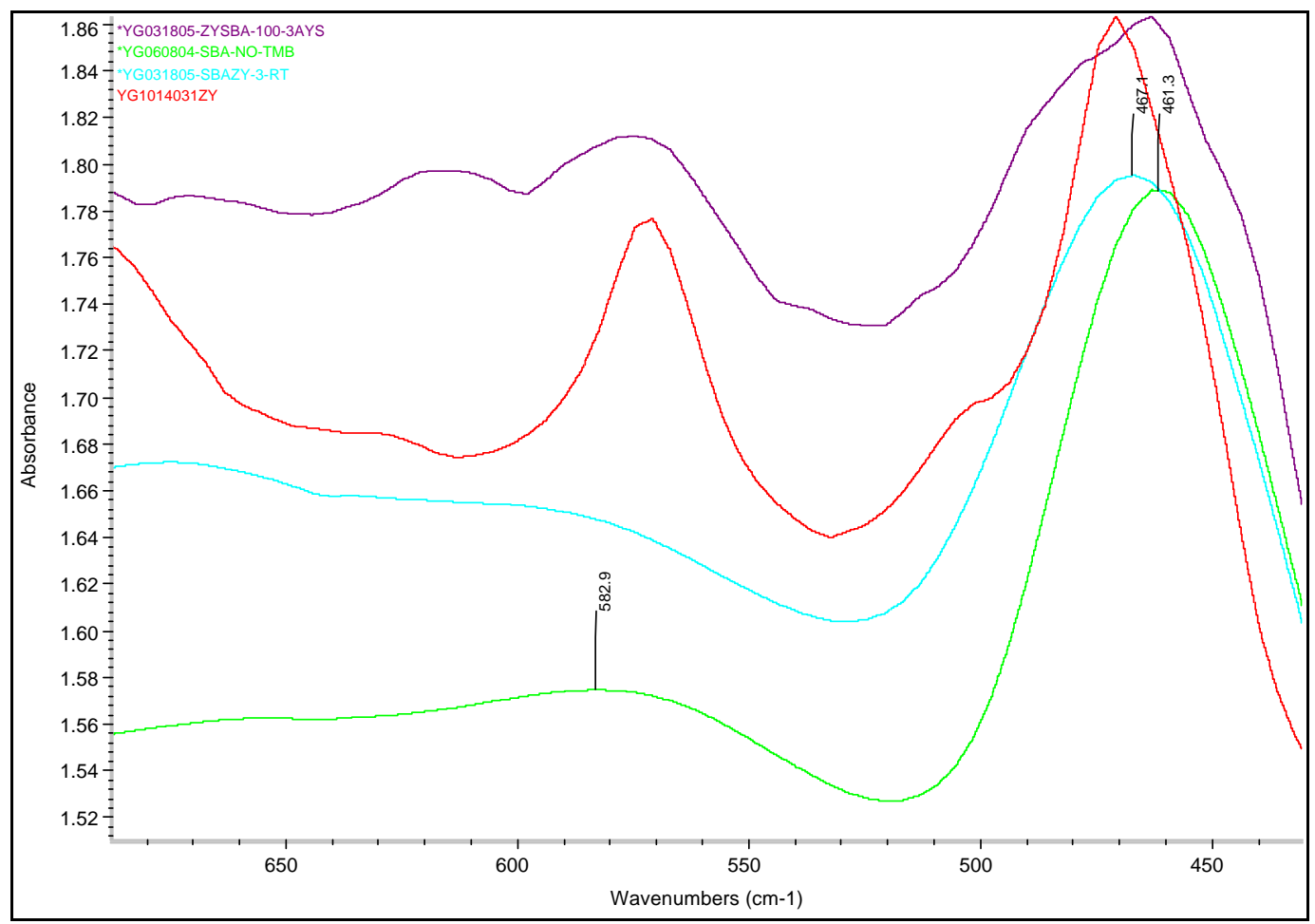

Figure 24: FTIR Spectra of (a) Pure SBA-15 synthesized in $\mathrm{H}_{2} \mathrm{SO}_{4}$ ( $4^{\text {th }}$ from top left), (b) Zeolite Y/SBA-15B ( $1^{\text {st }}$ from top left $)$, (c) Zeolite Y/SBA-15C ( $3^{\text {rd }}$ from top) and (d) Pure zeolite Y nanocrystals ( $2^{\text {nd }}$ from top left). 
Thermal Analysis: Figure 25 shows weight loss analysis curves for pure zeolite Y nanocrystals synthesized in the presence of $\mathrm{TMAOH} / \mathrm{Br}$ (broken line 070304) and pure SBA-15 synthesized from $\mathrm{H}_{2} \mathrm{SO}_{4}$ (solid line 030405). Weight loss events in the zeolite Y nanocrystals in the 200 to $400^{\circ} \mathrm{C}$ region are attributed to the decomposition of $\mathrm{TMAOH} / \mathrm{Br}$ entrapped within the pores of the zeolite. Weight loss in pure SBA-15 is attributed to the decomposition of P-123 copolymer entrapped within the mesopores. Figure $26^{`}$ shows weight loss events for the zeolite SBA-15 composite. Events between 175 and $400^{\circ} \mathrm{C}$ suggest the presence of both SBA-15 and zeolite Y phases.

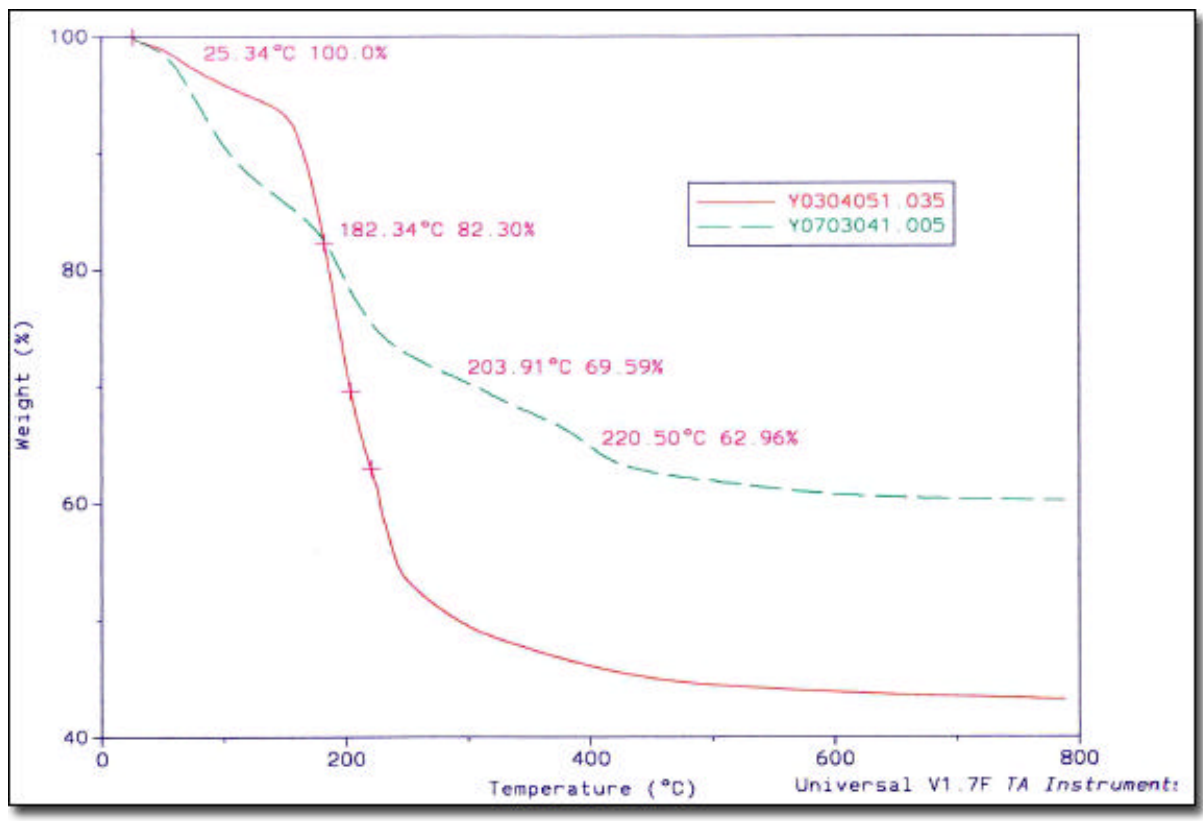

Figure 25: TGA Analysis of Pure nanocrystalline Zeolite Y (broken line with ID 070304) and Pure SBA-15 synthesized in sulfuric acid ( solid line with ID 030405) 


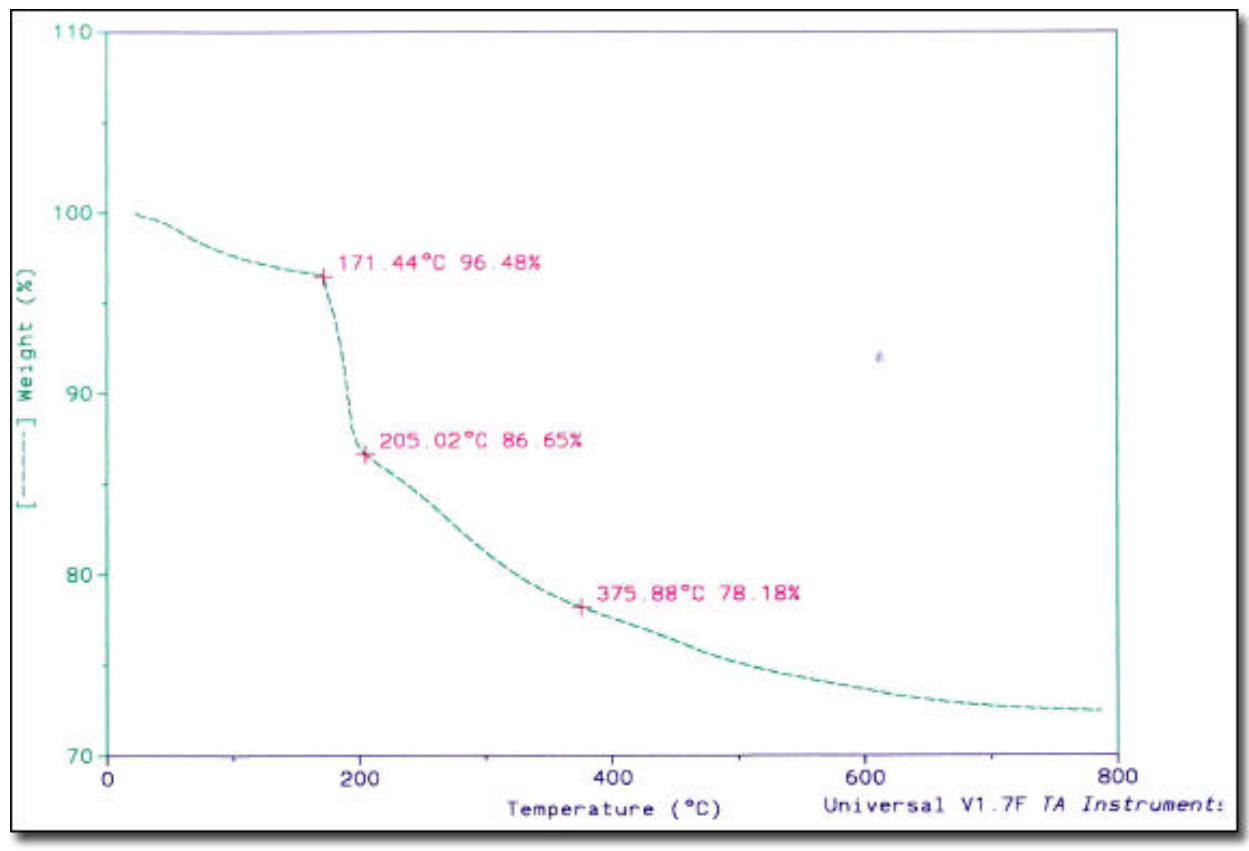

Figure 26: TGA Analysis of Zeolite Y /SBA-15 composite

\section{CONCLUSIONS}

The synthesis of high surface ordered nanoporous silica of expanded pore diameter of $25 \mathrm{~nm}$ (larger than the standard size of $8.4 \mathrm{~nm}$ ) using trimethylbenzene as a pore size expander was accomplished. The synthesis of zeolite Y nanoparticles with median pore size of approximately 50 $\mathrm{nm}$ (smaller than the $80 \mathrm{~nm}$ typically obtained with TMAOH) using combined TMABr/TMAOH as organic additives was also accomplished. The successful synthesis of zeoliteY/Nanoporous host composite materials by sequential combination of zeolite precursor mixtures and nanoporous material precursor mixtures was suggested from results from various characterization techniques such as X-Ray diffraction, infrared spectra, thermal analysis, porosimetry data. The composites were nanoporous of pore size larger than the pure nanoporous host. The surface area of the composite was also lower than the pure nanoporous hosts. Evidence of the presence of zeolite Y in the composite was observed in infrared spectrum. 


\section{FUTURE WORK}

Further characterization to understand the incorporation of zeolite $\mathrm{Y}$ precursor or small crystallites within the pores of SBA-15 will continue. To investigate this, we will convert all exchangeable ions to $\mathrm{H}+$ by ion exchange with ammonium nitrate, followed by calcinations at 550. The presence of any acid sites using the adsorption of absorption of bases such as ammonia or pyridine. Acid catalyzed reactions will be will also be used as a means to very the existence of Bronsted acid site from the presence of zeolite $\mathrm{Y}$ in the material. The catalytic performance of the zeolite Y/SBA-15 composite materials will be compared with that of pure SBA-15. The catalysts will then be evaluated for the conversion of heavy petroleum feedstocks.

\section{TECHNOLOGY/INFORMATION TRANSFER}

Students:

Two following two students have been working on the project since inception:

Yohannes Ghirmazion $\quad$ M.S. graduate student (Chemistry)

Fengling Ding M.S. graduate student (Chemistry)

Ifedapo Adeniyi Sophomore undergraduate (Chemistry \& Engineering)

Taurean Hodges M.S. graduate student (Chemistry)

Selassi Blavo Senior (Chemistry and Chemical Engineering)

\section{Presentations:}

1) Synthesis of Mesoporous Solids Containing Zeolitic Phase from Hydrothermal Treatment of Colloidal Zeolite Y Precursors submitted, by Yohannes Ghirmazion and Conrad W. Ingram, to be presented in the Materials Chemistry and Nanotechnology Symposium at

PACIFICHEM 2005 , Honolulu, December 15-20, 2005

2) Preparation of Nanosized micro/mesoporous composites via sequential synthesis of zeolite Y/SBA-15 phases; Yohannes Ghirmazion and Conrad W. Ingram, to be presented at the ACS National Meeting, Washington DC, August, 2005 .

3) On the Synthesis of Zeolite Y Nanocrystals in the Presence of Tetramethylammonium Bromide, Yohannes Ghirmazion* and Conrad W. Ingram, presentated at the 227 ACS National Meeting, Anaheim, California, March 28 - April 1, 2004.

4) Non Ionic Surfactant Mediated Templated Synthesis of Phenylene-Bridged Organosilicate, Yohannes Ghirmazion*, Conrad Ingram, presented at the 55th Southeast Regional Meeting (SERMACS), Atlanta, GA, November 16-19, 2003. 
5) A Comparison of Synthesis Strategies for Aryl Functionalized Ordered Nanoporous Organosilicates using Nononionic and Cationic Surfactants, Yohannes Ghirmazion*, Conrad Ingram presented at the 55th Southeast Regional Meeting (SERMACS), Atlanta, GA, November 16-19, 2003.

6) Phenylene-Bridged Mesoporous Organosilicate from Nonionic Surfactant Templated Synthesis, Conrad Ingram* and Yohannes Ghirmazion, presentated at the 4th International Mesostructured Material Symposium, May 1-4, 2004, Cape Tow, South Africa.

7) Synthesis of Aromatic Bridged Ordered Mesoporous Organosilicate with Cetyltrimethylammonium Cation as Templating Agent was presentated at the 4th International Mesostructured Material Symposium, May 1 -4, 2004, Cape Tow, South Africa.

\section{REFERENCES}

1. D. Zhao, J. Fing, Q. Huo, N. Melosh, G. Fredrickson, B. Chmelka, G. Stucky, Science, 279 (1998) 548-552; D. Zhao, Q. Huo, J Feng, B. F. Chmelka, G. Stucky, J. Am. Chem. Soc., 120, (1988) 6024-6036

2. D. Ginter in Verified Synthesis of Zeolitic Materials, H. Robson, ed. Elsevier: Amsterdam, (2001), 156.

3. M.M.J. Tracey, J. B. Higgins; Collection of Simulated XRD Powder Patterns for Zeolites, 4th ed. Elsevier: Amsterdam, 2001.

4. Szostak, R. In Handbook of Molecular Sieves Van Nostrand Reinhold; New York, 1992.

5. R. Ravishankar, C.E.A. Kirschhock; F. Vespeurt; P. J. Grobet; P. A. Jacobs; J. A. Martens, J. Phys. Chem. B. 1999, 103, 4965.

6. C. Shane Carr, S. Kaskel, and D. F. Shantz, Chem. Materials 16, 3139 -3146, 2004. 